\title{
VISIÓN ANDINA Y CHOLA DEL AGUA
}

\author{
Lic. Julio César Alfaro Moreno \\ Profesor del Departamento de Ciencias Humanas de la \\ Universidad Nacional Agraria La Molina \\ jalfaro@lamolina.edu.pe
}

\begin{abstract}
Resumen
El agua ha marcado la historia peruana y de gran parte de Latinoamérica, con ella se construyeron grandes culturas, que llamamos hidráulicas, y a través de los siglos se logró establecer una cultura andina del agua. Actualmente este bien es cada vez más escaso, por el histórico mal trato de nuestros recursos naturales y de las culturas originarias que los cuidaban y así también por el cambio climático. Y ahora tiene que abastecer tanto a los mismos andinos como a los campos y a las ciudades de la costa, por tanto, su cuidado representa un reto histórico de primera importancia. Para los andinos el agua es percibida como un ser vivo y divino que merece ser compensada por la intervención de los dioses y los mismos habitantes andinos. Así también, el agua es concebida como un ser articulador del universo y de los seres humanos, teniendo también dos lados, el que se construye a través de la agricultura y la ganadería y de los mismos seres humanos que viven del agua y el otro lado, el destructivo que produce huaicos y demás desastres como la helada o la sequía. El carácter constructivo del agua solo se puede solucionar en comunidad, en armonía, con un sentido de reciprocidad y equidad, solo la unión permitirá fortalecer el lado bueno y retar al malo para que no ocurran los desastres y si fuese así, evitar mayores dańos. Para que esta actitud de la comunidad sea la adecuada se requiere actuar, como la misma agua, con flexibilidad, fluidez y rapidez, como la veía Arguedas en su novela: Los ríos profundos.

Palabras claves: Agua, Interculturalidad, Organización social del agua, Cultura del agua, Modernidad andina, interculturalidad, cultura chola y criollo-occidental, mercado, estado y políticas interculturales y mestizaje.
\end{abstract}

\begin{abstract}
The water has marked the Peruvian history and of great part of Latin America, with it big cultures were constructed, and across the centuries it was achieved to establish an Andean culture of the water, now this good is increasingly scanty for the historical evil I treat of our natural resources and of the original cultures that they were taking care of them and for the climatic change. And now it has to supply so much to same Andean like to the cities of the coast. Therefore the water care represents a historical challenge of the first importance. For the Andean ones the water is perceived as an alive and divine being who deserves to be compensated and for the intervention of the gods and the same Andean inhabitants. This way also, the water belongs viewed as a being joint to the universe and to the human beings, having also two sides, because it constructs across the agriculture and the
\end{abstract}


cattle and of the same human beings who live of the water; and a destructive side that produces avalanches and other disasters, as the frost or the drought. The constructive character of the water only can be solved in community, in harmony, with a sense of reciprocity and equity, alone the union will allow to strengthen the good side and to challenge the villain in order that the disasters do not happen and if it was like that to avoid major damages. In order that this attitude of the community is the suitable one it is needed to act, as the same water, with flexibility, fluency and rapidity, since it José María Arguedas saw in his novel: The deep rivers.

Key words: Water, multiculturalism, social organization of water, water culture, modern Andean, culture Chola and Creole-Western, market, state, political-cultural, cross-breeding.

\section{Introducción}

Este artículo se inició en un estudio que hicimos, en el 2004, para una organización latinoamericana promovida por la ONG CIED Perú, llamada Recursos Hídricos en el Altiplano, que comprometió a ONGs y organizaciones indígenas de Bolivia, Argentina y Chile, con el apoyo de CONDESAN. Tenía como uno de sus fines que cada país reconstruyera la lógica de la visión andina del agua, rescatando la eficiencia del agua, los derechos y tradiciones de los indígenas y protegiera los ecosistemas. A nosotros nos toco el caso peruano, que se expuso en un seminario especializado, aunque no se publicó. Posteriormente, en el 2005, se corrigió y aumentó el texto para presentarlo en el III Congreso Latinoamericano de Cuencas, organizado por la Red Latinoamericana de Manejo de Cuencas de la FAO, el cual, pudo concitar un singular interés de parte de los congresistas, aunque por la cantidad de ponencias y por los límites presupuestales de la FAO, no se publicó, como texto físico. Posteriormente, del 2006 al 2010, se mejoró, aumentó y corrigió especialmente para la revista
Tierra Nuestra, a fin de que sea publicado, de esta manera, le entregamos al lector una versión extendida y madurada durante cinco años.

La motivación que se tuvo para hacerla es la necesidad de rescatar que existen diversas visiones del agua en nuestros países. La diversidad cultural afecta a diversos órdenes de la vida tecnológica, social y humana de los actores sociales y también al agua. Muchas veces los estados latinoamericanos erigen sus política del agua, considerando que la única cultura existente es la occidental y que no existen otras culturas del agua y hacen sus leyes, medidas y organizaciones, con este supuesto y cuando intentan poner en práctica dichas políticas tienen a fracasar o a tener una respuesta no esperada por ellos. $\mathrm{Y}$ es porque pocas veces se han puesto a pensar que existen diversas culturas del agua y que son $\tan$ rescatables las unas como las otras así como que puede haber una síntesis o convergencia entre ellas.

Así también nos interesa exponen cómo evoluciona la visión andina hasta la actualidad y presentar las diversas variables que hacen que sus contenidos 
se modifiquen de un lugar a otro, de una región a otras y también de una comunidad a la otra.

1. Contexto de la Geografía andina y la construcción de una cultura del agua

La geografía del Perú, así como la de los otros países andinos, está marcada por la presencia maciza de la cordillera de los andes, la cual, le ofrece a las poblaciones andinas y a los actores sociales de las cuencas andinas, tanto sus potencialidades como sus límites.

Todo ello debido al carácter accidentado y diverso del territorio andino con zonas de muy variada altitud (de los 500 a 5000 m.s.n.m), pendientes (del 1\% al 100\%), climas variados (frígidos y calientes bajo el sol) y un sinnúmero de microclimas, tipos de suelo (todos los horizontes) y a los significativos riesgos de desastres que han desaparecido o han puesto en peligro de desaparecer a muchas culturas andinas, (Chavín, Tiahuanuco, Wari, y otras) e incluso ciudades andinas enteras (Yungay, etc). Territorio que es teatro de una diversidad de culturas y subculturas que varían según su experiencia histórica, su ubicación en los pisos ecológicos, zonas de producción y cuencas donde se encuentren.

\section{a) Las potencialidades}

La presencia de la cordillera andina marca una biodiversidad muy grande, trayendo como por consecuencia, que nuestros países produzcan una alta variedad de tipos de agua, suelos, cultivos como los conocidos mundial y tradicionalmente: como la papa y el maíz; crianzas como las llamas, alpacas y vicuñas. Así como los otros productos o seres vivos, difundidos, en forma masiva, recientemente, como es el caso de cultivos como la maca, coca, quinua, quihuisha, cañihua; o como en el caso de los animales, como las vicuñas, guanacos y nuevas especies de ovinos readaptadas al área andina como la raza Junín y otras. Así también una diversidad muy amplia de minerales como el oro, plata, cobre, zinc, etc. y una variedad, más limitada, de aves y animales silvestres.

Esta biodiversidad ha sido motivo de admiración de los promotores del desarrollo y los investigadores del mundo. La defensa de la misma biodiversidad tiene como una de sus grandes tareas a la conservación o mejoramiento de la cantidad y sobre todo la calidad del agua, que garantiza la supervivencia de todos los seres vivos de la región andina.

Más aún, no con una visión más amplia, se podría concebir que el área andina abarca todo el territorio del Perú y el de los diversos países andinos o los que por lo menos, tienen una parte andina como Chile y Argentina. Es decir, que podría abarcar desde las partes más altas llamadas jalcas, cuyas aguas, vienen desde los 6,000 metros sobre el nivel mar hasta los pies de las montañas: Tanto las partes bajas de las cuencas andinas occidentales que derivan en el océano pacífico, cuyas aguas caen desde 500 a 0 metros, llamada costa o simplemente chala, como las partes bajas de las cuencas orientales que derivan en el océano atlántico, nominadas selva alta o rupa rupa y selva baja o omagua, cuyas aguas caen desde los 1000 a 0 metros.

La chala tiene escasa vegetación y el agua 
que utiliza provenga de las partes altas y medias de las montañas andinas y está destinada finalmente al consumo de la población, a la electricidad y al desarrollo de la agricultura costeńa. Asimismo, en la chala se encuentra el principal volumen de fuerza de trabajo y de creatividad empresarial con las micro, pequeñas y medianas empresas, cuyas aguas y seres humanos, también provienen de las partes altas de las cuencas del Pacífico. Con elementos culturales milenarios procedentes de altas culturas como la Nazca, Paracas, Chimú, Moche y otras y en la actualidad sirve de asiento o habitad de la población mayoritaria del país. Con la migración masiva desde las partes altas hacia la chala, se ha constituido un nuevo grupo humano, que viniendo de las culturas andinas de las montañas, se han insertado en las ciudades, incorporando elementos de las cultura moderna occidental, readaptándolas a su cultura original, la que también ha tenido transformaciones importantes. La cultura de este nuevo grupo se la dado en llamar cultura chola. Posteriormente, la choledad rebota a las mismas montañas andinas como reseño más adelante.

Esta incorporación de lo occidental dentro de las culturas andinas originarias, generó esta cultura chola, transformando la idea de lo colectivo, propio de las culturas andinas en una red de familias extensas, vinculadas a través de clubs departamentales, provinciales y distritales, formando microempresas o pequeñas empresas, incorporando la cumbia costera occidental dentro del huayno que ha dado lugar a diferentes géneros musicales $y$ versiones como la chicha, el huayno con arpa, etc.

Asimismo, en segundo lugar, las montañas andinas podrían abarcar, los otros pies de montaña, que son las partes bajas de las cuencas andinas del Atlántico, que a su vez tienen dos subpartes, la primera subparte se ha dado en llamar selva alta o ruparupa y la segunda selva baja o omahua:

La primera subparte, recepciona el agua de la cordillera, con una larga y amplia vegetación agrícola (coca, cacao, café. Frutales, etc) y forestal, que vendría ser una prolongación de las montañas andinas. Al haber sido ocupada por una población mayoritariamente andina, sea como colonos o trabajadores eventuales, quienes han formado una población organizada, con elementos culturales andinos transfromados como la reciprocidad, el espíritu de grupo, la identificación con la naturaleza, etc. Y también con elementos culturales criollo occidentales como la creación de un sinnúmero de asociaciones por productos, sindicatos, lucha gremial (toma de carreteras) y especialización en un solo cultivo como el café o la coca. Haciendo que la choledad también se amplíe hacia la selva.

La segunda. subparte recibe también el agua de la cordillera, agregando a la que ya existe, constituyendo las partes bajas de las cuencas, de mayor volumen hídrico del país, absorbiendo el $97 \%$ del agua de las mismas. Se trata de una inmensa llanura, a desnivel, con una frondosa vegetación arbórea, cuyos suelos no son tan aptos para una agricultura masiva, sino para una ganadería estabulada y una explotación forestal discriminada y planificada, con una agroindustria forestal fina, para evitar la deforestación masiva en detrimento del 
máximo pulmón de América Latina, que es la amazonía.

En la primera y segunda sub-partes también se han formado dentro de las ciudades de la rupa rupa una cultura chola, que comporta elementos de las culturas amazónicas previas, la cultura andina y los elementos de la cultura occidental, traídos por los mestizos migrantes de la chala y de las montañas andinas.

\section{b) Las limitaciones}

El otro 3\% del volumen de agua es utilizada por la gran mayoría de la población peruana, sea para regar sus tierras agrícolas, para consumo doméstico o para el funcionamiento de las empresas como las hidroeléctricas, mineras e industriales. De esta manera se satisface las necesidades de agua tanto de la Chala y de los pisos ecológicos altos, donde se concentra la población peruana.

Esta es una gran paradoja: la parte más poblada y agrícola o ganadera del territorio peruano solo puede disfrutar del $3 \%$ de volumen de agua nacional y la parte menos poblada y no agrícola del país dispone del 97\% del volumen de agua nacional. Es decir que los espacios netamente andinos y costeños tienen un volumen muy limitado de agua, presentando una milenaria escasez, al no poder trasferirse el gran volumen hídrico de las selvas, tanto por el alto costo que tendría el traslado de dicha agua, como en lo difícil que resultaría éste transvase a través de las frondosas u pétreas montañas andinas. $\mathrm{Y}$ también porque efectivamente una parte importante de esta agua es requerida por la frondosa vegetación amazónica, cuyas posibilidades económicas y turísticas futuras son enormes.

De tal manera que los hombres y mujeres andinas tienen que vivir con los limitados recursos hídricos que llegan directamente del territorio estrictamente andino, durante solo de tres a cinco meses de lluvias, en el mejor de los casos. Asimismo tiene que compartir dicha agua con la costa peruana, bañada por el océano pacífico, donde no llueve prácticamente nada y que ha construido una ingente cantidad de canales de riego durante estos últimos cincuenta años, representando la principal inversión del Estado en este período. En este sentido, las poblaciones andinas tienen como uno de sus principales retos la atracción o cosecha del agua de la lluvia, la conservación de la misma en sus suelos y en la vegetación, sin que se deslice hacia los ríos; su uso óptimo y racional por las actividades humanas como el uso doméstico, económico y ritual; su distribución equitativa para satisfacer la demanda de la agricultura a través de una infraestructura hidráulica que revierta el carácter semiárido de sus suelos, la operación y mantenimiento de dicha infraestructura, sometida frecuentemente a los desastres, como los deslizamientos e inundaciones, entre otros; y la reproducción de la calidad de las fuentes de agua a través de un efectivo manejo y gestión de cuencas de carácter integral.

\section{c) Los retos}

En otras palabras, la biodiversidad como riqueza y a la vez, con un limitado volumen hídrico han condicionado a que la población andina haya tenido a lo largo de su historia los siguientes retos: 
1 Sostener una población indígena y chola milenaria creciente, en términos absolutos, aun así, con las tremendas oleadas migratorias del ande hacia las grandes ciudades de la costa desde los 50 del siglo XX hasta hoy. La ocupación territorial, estrictamente andina, sigue siendo significativa, alrededor de siete millones de habitantes, en medio de una geografía compuesta de laderas y con temperaturas muy bajas. Y si entendiéramos en forma amplia, el reto de lo andino es sostener a la gran mayoría de la población peruana y al desarrollo del país.

2 Volver, con mayor intensidad, a un uso racional y óptimo de la agricultura de laderas que se practicaba desde la época prehispánica, debido a los estrechos valles y a la deficiencia de los mismos para garantizar su seguridad alimentaria y a la creciente población en términos absolutos, aunque si exista una despoblación de las montañas andinas. Y sobre todo a la gran demanda de la población de las costa o chala. Esto la está obligando a tener que volver a explotar racionalmente las laderas, evitando que el agua caiga y arrastre los suelos, tratando que se quede y penetre en los mismos. De esta manera se evita que el suelo no se desprenda y derive en los ríos para volverlos poco aprovechables por la población de las partes bajas, donde se ubican las ciudades.

3. Rehabilitar una infraestructura prehispánica, donde inmensas terrazas, a lo largo de su historia, llamadas antiguamente patas-patas y actualmente andenes, muchas de ellas abandonadas (se calcula el 70\%) y en estados diversos de deterioro.
4. Repotenciar los cultivos andinos no solo por la demanda interna sino porque potencialmente tienen una creciente demanda internacional para la exportación (como la quinua, la quihuisha, la maca, etc.). La estrategia de los andinos ha sido de seguridad alimentarla, con una variada sumamente grande de cultivos andinos, que se ubicaban en diversos pisos altitudinales, que crecen en una diversidad de microclimas y tipos de suelos y en altitudes muy diferentes. Por ello, cada familia y cada comunidad se cuidó de tener muchas parcelas y zonas de producción, aunque en las últimas décadas, esta amplitud ha sido reducida, ante las demandas inmediatas y especializadas del mercado y por las grandes distancias con relación al mismo, concentrado la población en las ciudades de la chala y ceja de selva.

5. Aprovechar al máximo sus diversos lagos, lagunas y puquiales para el consumo doméstico de las familias y animales, para el desarrollo de la agricultura y sobre todo de la ganadería, con técnicas que no los deterioren. Tratando de que dichas fuentes de agua sean "criadas" o tratadas con el máximo cuidado. Son 25000 lagos y lagunas y una inmensidad de puquiales, que si se le otorga todo el valor que se merecen, pueden ser de suma utilidad para mantener el potencial del volumen hídrico de nuestros andes y garantizar que las partes altas de las cuencas, mantengan el volumen hídrico necesario, en beneficio de las partes altas, medias y bajas; es decir, de todo el territorio nacional.

6. Tratar de promover la mejor convivencia posible entre la actividad agrícola y la 
minera a través de diálogo y la equidad, las concesiones mutuas, el cuidado ambiental y un sistema de compensaciones de los afectados por la minería sin que pierdan los agricultores su trabajo permanente con una estrategia de desarrollo adecuado a las montañas andinas.

7. Distribuir eficiente y equitativamente el agua en sus diversos usos a través de la concertación de todos los actores, llamados usuarios del agua, sea la población de las ciudades, los regantes, las industrias, las minas, etc. a través de autoridades de cuencas y microcuencas.

8. Enfrentar a una variedad de enormes riesgos y desastres muy relacionados con la presencia desigual del agua y a la velocidad que adquiere su caída a través de las laderas andinas. Los cinco meses de lluvias en algunos años, son muy intensos, generando enormes desastres en los lugares no cubiertos por terrazas o andenes o deforestados o con pastos o cultivos desnudos o semidesnudos, cayendo aludes que adquieren el nombre de huaicos. Para el hombre y mujer andinos son tan importantes, estos desastres, que a la propia cuenca le llaman huayco, por donde transcurre ese inmenso arsenal de lodo y piedras que arrasa con sus caseríos y ciudades.

Así como lo plantea Luis Revilla y los investigadores del CESA, analizando la microcuenca del Quencomayo en la provincia de Paucartambo en Cusco (CESA 1999).

Hasta en los lugares con andenes más o menos bien construidos, con regular forestación y frondosos pastizales, se presentan algunos derrumbes de los muros de los mismos andenes, causando cierta erosión de los suelos y algunos deslizamientos. Los ocho meses de sequía también se prolongan hasta cubrir casi todo el año, generándose cada cierto tiempo, enormes sequías, que arrasan con la calidad de vida de la gente, provocando desplazamientos de la población hacia los pies de montaña y provocando hambrunas periódicas.

Un riesgo que merece ser destacado son las periódicas heladas desde mayo hasta agosto, afectando a gran parte de los cultivos, deteriorando la salud de la población humana, con frecuentes enfermedades bronco pulmonares $y$ respiratorias y a la población animal, teniendo que crear microclimas artificiales, a través de hogueras provocadas con material inflamable (leña, pastos secos, etc) con el concurso de todos los miembros de la comunidad, tratando de atacar o neutralizar, con el humo, esta agua helada, convertida en viento, llamada heladas o circulando el agua de riego para neutralizar el impacto de dichas heladas, aunque esta tecnología es conocida solo por un sector limitado de la población andina.

9. Satisfacer crecientemente las demandas implacables del mercado. Una demanda creciente del mercado obliga a las poblaciones andinas a desaprovechar sus condiciones favorables a la propulsión de la biodiversidad, al concentrase cada vez más en algunos productos como la papa, la maca, la quinua, reduciendo su variado portafolio de cultivos andinos. El mercado les exige un mayor volumen de sus productos y las poblaciones andinas tienen 
limitadas condiciones de desplazamiento rápido de sus productos, al disponer de precarios caminos y carreteras, desde sus centros de producción a la carretera más cercana y de esta a las ciudades. La respuesta ante estas dificultades de desplazamiento, todavía sigue siendo, vender al comerciante en chacra, quien les ofrece irrisorios precios, provocando la retroalimentación de la pobreza de las familias andinas, las cuales, disponen de escasos ingresos pecuniarios y han tenido que reducir sus productos alimentarios andinos a favor de los del mercado.

El mercado les exige también una demanda de una importante suma de productos y los campesinos andinos responden interesándose solamente en los andenes, con agua de riego, que permiten ciertos cultivos rentables que demanda el mercado, a fin de que aumenten la productividad del suelo, al tener mayor humedad en provecho de sus ingresos monetarios. Aun así el limitado hectareaje promedio de los andinos impide entrar a una economía de escala, salvo que se concerten alianzas entre los productores, por microcuencas, con la figura de las cadenas productivas.
- Todos estos retos antedichos generan el reto de construir una cultura del agua, que supone una alta valoración de la misma y un respeto altamente idealizado y místico, que conducirá a que el andino, en forma esmerada la cuide, no la desperdicie, racionalice su uso y la destine adecuadamente a sus diversos fines. A través de los estudios históricos se ha comprobado que este reto fue cubierto con creces, como lo vamos a ver más adelante.

De esta manera se ha generado una cultura sui generis en el área andina alrededor del recurso aguay tierra, exaltado un cuidadoso tratamiento y respeto. Esta cultura además se caracteriza por su espíritu comunitario, visión integral y animada del cosmos, de la vida, un espíritu abierto a captar elementos de otras culturas para recrearla con la suya. Y una sui generis combinación de la dimensión colectiva con la individual. Sólo las oleadas migratorias, la menor densidad demográfica de la comunidad y la incorporación de los valores del mercado han golpeado relativamente esta cultura que se encuentra en un proceso de reorientación hacia la cultura chola. La choledad hasta el momento ha sido vista como una adopción de los migrantes en

Cuadro 1: Uso actual consuntivo del agua por vertientes

\begin{tabular}{|l|r|r|r|r|r|r|}
\hline \multicolumn{1}{|c|}{ Vertiente } & \multicolumn{1}{c|}{ Agrícola } & Poblacional & Industrial & \multicolumn{1}{c|}{ Minero } & \multicolumn{1}{c|}{ Pecuario } & \multicolumn{1}{c|}{ Total } \\
\hline \multicolumn{1}{|c|}{ Pacífico } & $11^{\prime} 987,643$ & 722,289 & 149,338 & 70,463 & 23,335 & $12^{\prime} 953,883$ \\
\hline Atlántico & $1^{\prime} 996,268$ & 162,056 & 6,370 & 42,566 & 38,150 & $4{ }^{\prime} 042,899$ \\
\hline Titicaca & 71,077 & 12,056 & 132 & 965 & 9,148 & 93,148 \\
\hline Total & $144^{\prime} 054,988$ & 896,971 & 156,340 & 113,994 & 70,633 & $15^{\prime} 292,424$ \\
\hline \% del total & 91.9 & 5.9 & 1.0 & 0.8 & 0.4 & 100 \\
\hline
\end{tabular}


las ciudades, sin embargo, se considera que esta choledad también se está proyectando en el propio campo.

2. La situación de los recursos hídricos para el riego en el país y la cultura ancestral del agua

Como se ha afirmado, los recursos hídricos son limitados porque tanto la demanda como la oferta de agua, se encuentra concentrada, en un territorio árido en la costa peruana, que es la parte baja de la vertiente occidental, donde se encuentran las 62 cuencas o unidades hidrográficas del Pacífico, cuyas partes medias y altas se ubican dentro del área estrictamente andina; semiárido, donde se encuentran las partes altas y un sector de las medias de las 39 grandes cuencas del Atlántico con el otro sector de las partes medias y sobre todo de las bajas con mayor potencial hídrico. Este bajo volumen de recursos disponibles tiende a reducirse, con la deglaciación de las altas cumbres, que son la fuente de agua de los lagos y lagunas y de los ríos, los cuales representan buena parte de la oferta de agua del país.

Si a ello agregamos, las grandes dificultades que se tienen para captar el agua de lluvia o subterránea al no haberse continuado con las ancestrales prácticas como las cochas y las chacras hundidas, por el histórico desconocimiento y subestimación del estado y sociedad civil urbanas republicanas, respecto a estas tecnologías y prácticas tradicionales. Todo ello porque el Estado y las instituciones eran controladas por una minoritaria población criollooccidental, ubicada en las ciudades de la costa. Desconociendo, desde la esfera del Estado e incluso las universidades, el inmenso acervo tecnológico andino. Sólo en los últimos veinte años se ha iniciado la revaloración de dichas tecnologías por un sector importante de las ONG y algunas entidades estatales como el PRONAMACHCS, MARENAS y otras, las cuales, al fusionarse en el año 2009, en una solo entidad llamada Agro Rural, conformada también por otras entidades de promoción de la producción para el mercado, corren el peligro de diluirse en su finalidad estratégica.

Así también las fuentes de agua están expuestas a la contaminación de parte de las empresas mineras que botan sus relaves a los ríos y lagos o lagunas; asimismo ocurre con los deshechos domésticos y los desagües de las crecientes ciudades y del uso indiscriminado de químicos para prevenir las enfermedades de los animales y de las plantas, los cuales, en los últimos años, están siendo regulados por las entidades estatales correspondientes (INRENA y SENASA). Aunque INRENA, desde del mismo 2009, ha desaparecido, en función de una sola entidad dedicada al agua llamada ANA. Y las otras funciones del otrora INRENA, se quedado como direcciones de los Ministerios de Agricultura y de Medio Ambiente. Estas sociedades andinas han venido desarrollándose, creándose ciudades, empresas y diferentes actividades económicas que hacen que el agua adquiera diferentes usos consuntivos, como podemos observar en el cuadro $\mathrm{n}^{\circ} 1$, donde podemos constatar que la agricultura absorbe el mayor volumen de agua, seguido del consumo poblacional y en menor medida de la actividad industrial, siguiéndole muy de cerca la 
actividad minera.

En este cuadro se puede ver que la cuenca del pacífico es la que absorbe la mayor cantidad de agua que se consume, provocando que la infraestructura hidráulica se centre en las cuencas de este océano. Aun así el potencial hídrico, suelos, agricultura del Atlántico es mucho mayor y en donde la población andina también es mayor, creándose una falta de equidad en la instalación tanto del agua de riego como de las otras actividades económicas.

a) Organización de los usuarios del riego La más importante organización social del agua son las juntas y comisiones de regantes que fueron promovidas por el Ministerio de Agricultura a partir de la ley de agua vigente, tratando de ordenar el sistema de riego del país.

El modelo en que se basaba dicha organización, fue de las condiciones naturales, sociales y culturales de la agricultura de la costa, a partir de una organización especializada muy propia de esta parte del Perú, compuesta de tierras planas o semiplanas, orientadas a satisfacer la demanda de las grandes ciudades del país y del exterior. En el mundo andino, las organizaciones encargadas del riego, especialmente en el centro y sur, fueron y de alguna manera lo siguen siendo las comunidades campesinas. Éstas son de carácter integral, es decir, contemplan toda la problemática de los habitantes andinos y se identifican con un territorio llamado comunal que abarca ríos, suelos, pastizales, bosquetes, etc. Dentro de sus tareas, una de ellas es la organización social del riego y están ligadas parcial y fragmentariamente al mercado.

Las autoridades estatales llevaron el modelo organizacional de las juntas al ande con limitados resultados. Una parte de las comunidades decidieron obviar la ley y dichas organizaciones, continúan su funcionamiento de acuerdo a sus prácticas y derecho consetudinario y otra lo aceptaron, aunque tratando de conservar aspectos importantes de sus organizaciones tradicionales. Es decir, se asumió la apuesta de la modernidad sintetizándola con su tradicionalidad, tratando de sacar provecho de ambas.

Es por ello que el ande solo tiene 32 juntas de usuarios frente a 75 de la costa y selva, es decir, solo el $30 \%$ de las juntas de usuarios se encuentran en el ande, pese a que éste abarca el $60 \%$ de las tierras agrícolas del país. Es de notar que el departamento del ande, con mayor cantidad de usuarios ,es Arequipa que se ha convertido en el espacio de mayor modernización y modernidad en el ande. Es por ello, que proyectos como el PRODERM y MARENAS, consideraban que en este lugar se encontraban los maestros andinos del riego, es decir los "yachachis" y los tomaron como capacitadores de los campesinos del Cusco, Puno, Ayacucho y Apurimac, para favorecer la actitud más abierta al mercado de los campesinos andinos. Sobre todo de la parte de comunidades campesinas, en proceso de modernización, sin negar aspectos importantes de su rica tradicionalidad y cultura tecnológica; es decir, sin negar su visión andina del agua, sino al contrario incorporarla a la nueva visión tecnológica. 
b) La construcción original de la cultura andina del agua.

Las potencialidades, los límites, los retos, la experiencia histórica de los andinos y las tareas del riego agrícola han condicionado a que se construya una cultura del agua por parte de las poblaciones andinas, milenariamente posesionarias $\mathrm{o}$ propietarias de las partes altas y medias de las cuencas peruanas, las cuales tienen dos dimensiones:

o La colectiva a través de la reciprocidad, muchas veces concertada mediante asambleas y relaciones interfamiliares para el buen uso del agua, lo que supone un tratamiento colectivo de los recursos naturales, como el agua, los trabajos y ritos colectivos. Esta colectividad se expresa a través de la ayuda mutua entre familias y toda la comunidad mediante el mecanismo andino de trabajo que es la reciprocidad;

o y la individual a través del uso de las parcelas o chacras individuales que requieren agua de riego, animales, casas, familias que beben agua y algunas actividades artesanales e industriales que requieren también de agua para su funcionamiento. Todo ello obliga a una dotación dosificada de agua $y$ el cumplimiento de ciertos deberes y derechos que forman parte de lo privado y lo colectivo en las comunidades y caseríos andinos.

Esta cultura del agua les ha permitido sobrevivir y florecer a lo largo de su historia, especialmente prehispánica, siendo la admiración de investigadores y promotores del desarrollo extranjeros, quienes se maravillan al examinar cómo ha podido vivir por tantos siglos, una población, en las peores o aparentemente desfavorables condiciones climáticas y limitados recursos hídricos, aunque con una riqueza humana y natural amplia y biodiversa.

Al vivir milenariamente dentro del mundo andino, las poblaciones han construido una visión o enfoque del agua que es más una experiencia viva de prácticas y actitudes que un cuadro coherente y sistematizado de ideas. Esta visión no es compartida en forma uniforme por la población andina, que también es diversa en sus visiones del agua, por motivo de que los grupos andinos se ubican en diferentes pisos ecológicos y zonas agroecológicas, con diversas posibilidades de vida; por ubicarse en diferentes cuencas hidrográficas sea en el Pacífico, Atlántico o Titicaca y por tanto tener una diversidad de recursos naturales y humanos $y$, por tanto, de culturas del agua.

Asimismo por pertenecer a diferentes culturales regionales andinas, incluso con muchos conflictos entre sí, como los aymaras versus los quechuas, los aymaras y los de Arequipa o los Huancas entre sí; asimismo, por pertenecer a distintas generaciones, géneros y de acuerdo a la mayor cercanía a las ciudades y al mercado. Todo ello hace que existan diversas visiones andinas del agua y no una sola como fácilmente podría concluirse. Basta decir cómo es que las culturas andinas ubicadas en el norte del país no tienen como eje de organización social a las comunidades campesinas, como si lo es para las culturas andinas del centro y 
sur del país. El eje para las del norte es la ayuda mutua entre familias campesinas y la voluntad individual del uso de las parcelas agrícolas y de las familias que viven en el campo y la ciudad.

Por ello fue muy fácil que el esquema organizativo del uso de agua de riego propuesto o impuesto por el Estado Nacional, a través de la formación de juntas de usuarios, prendiera en el norte y más difícilmente en el centro y menos en el Sur, salvo en las área con mayor influencia de la cultura criollooccidental como Arequipa. En el mismo centro, el municipio ocupa un papel competitivo con las comunidades en las localidades, teniendo que desarrollarse una alianza entre autoridades para ejercer la gobernabilidad local, la que está por encima de las juntas de usuarios.

En cambio, solo en parte ocurre este proceso en el sur, manteniéndose las comunidades con una importancia predominante aunque relativa. El gran desafío de este trabajo es dar cuenta de la unidad básica de esta visión andina del agua entre la diversidad de visiones que se han constituido, producto de las distintas experiencias históricas unidas bajo el epíteto de lo andino y visualizar las importantes visiones andinas del agua a su interior.

c) ¿Existe una visión andina del agua?

Podríamos a grandes rasgos reconocer que, en forma genérica, existe una visión andina del agua que ha venido teniendo profundas transformaciones, continuidades y discontinuidades a lo largo de su historia milenaria y que ahora asume la forma de la versión chola. Sin embargo, si nos quedamos en esta visión genérica podríamos dejar de lado la alta diversidad de visiones andinas del agua y de las culturas cholas.

Por tanto optaremos a exponer tanto la unidad como la diversidad de las visiones andinas del agua. Respetando la misma cultura andina, en la cual todo tiene varios lados como los de arriba y los de abajo, tanto las márgenes derechas como las izquierdas de los ríos, los cuatro suyos, etc.

$\mathrm{Y}$ es más no existe una visión andina uniforme ni siquiera dentro de las culturas regionales andinas. Los rasgos de la visión andina original de agua en cada cuenca, subcuenca, microcrocuencas, distrito, comunidad o caserío, ha venido conservándose en algunos de sus rasgos y abandonándose en otros o generando formas de interculturalidad $o$ de aculturación. De tal manera, que en la actualidad los rasgos que vamos a exponer a continuación se han venido fraccionando en algunos lugares y alcanzando nuevas síntesis en otros. En algunos lugares se conservan con la coherencia de los rasgos originales, en otros se han transformado a la luz de un proceso de cholificación, es decir, un proceso de incorporación de elementos importantes de la otra cultura occidental criolla o occidental a secas.

Y en otros lugares, después de dos o más generaciones. Se ha logrado formar una cultura mestiza, incluso en algunos lugares considerados como tradicionales como Cusco, zona altina del valle del mantaro, etc. Sin embargo, solo por presentar rasgos con mayor claridad presentamos una visión sistémica y coherente, a la 
manera de los tipos ideales de Weber, que reconocían que habían tres tipos de dominación, la racional, la tradicional y la carismática. A la hora de la realidad, estos tipos no se presentan en toda su pureza y solo sirven para comprender la realidad.

3. La visión andina del origen del agua se transforma en tensión y diálogo con la cultura criollo occidental o la cultura occidental a secas

\section{a) El origen del agua \\ El origen del uso del agua está vinculado al mismo origen del hombre y su sociedad. A la leyenda que cuenta que los incas salieron del lago Titicaca para buscar mejores tierras, otorgándonos la imagen de que la base del mundo es el agua. Gira en el mismo sentido, la otra leyenda de los hermanos Ayar, quienes salen de los cerros y buscan, dónde existen las mejores tierras humedecidas por el agua, para edificar su sociedad.}

Diversos autores como Greslou, Gelles, Escalante, entre otros, señalan que la base de las aguas se encuentra en el mar, como origen de todas ellas. Desde allí se esparce y penetra avanzando hacia arriba, desde las partes bajas de los cerros hacia arriba, cruzándose con el agua que cae del cielo y se conduce hasta abajo.

Con esta tesis se da pie a la construcción de las culturas de la costa, en el origen del mundo. Existen, así, los grandes movimientos geográficos y humanos, hasta llegar a las cumbres.

Desde los nevados, se llega a los cerros, donde existen seres animados y divinos como los apus, que según Gelles "botan voluntariamente el agua” según su satisfacción o insatisfacción, de allí la necesidad de los ritos del agua, es decir, que "las montańas provean el agua". En dichas montañas, se percibe que existe "una virgen que bota el agua," según sus investigaciones en Canabaconde, cuenca del Colca en Arequipa. Una vez que existe una autorización de los seres divinos para hacer circular el agua mediante sus venas (Greslou, 2001), esta llega a los lagos y lagunas como si fueran grandes depósitos que guardan también divinidades, para desde allí, repartirse hacia los ríos, puquiales y manantiales que contienen seres animados caprichosos.

La particularidad de la cultura andina es que concibe un binomio agua-tierra que es valorado por encima de los otros recursos naturales (Escalante 2,001) como el fuego y el aire. Sin embargo, la visión andina del agua no se queda en la superficie de la tierra. La misma Escalante dice que según sus entrevistas y testimonios en la cuenca del Colca en Arequipa y en las provincias altas del Cusco, los andinos ven al cielo como una sublimación de la tierra, como una Vía Láctea, que está surcada al igual que la tierra, que a su vez genera el agua que después baja a la tierra. En síntesis, son las montañas el gran reservorio del agua, de tal manera que su provisión depende de los seres que habitan en ellas y la hacen circular, a partir de una visión del cosmos en general.

Dentro de esta visión andina del origen del agua, según Greslou, desde sus primeros orígenes, fue creada por Tisi $\mathrm{W}(\mathrm{V})$ iracocha que anima la vida, la que se encuentra directamente ligada al agua. Sin embargo, con las influencias culturales 
posteriores, como la cultura Occidental, se superpone y se amalgama con la religión cristiana y católica, cuando señalan que la Virgen crea el agua y la bota hacia tierra, como lo plantea el mismo Gelles. Finalmente, ¿Cuál es el origen, ancestral andino o occidental?

A nuestro entender, son los dos en una inter influencia constante, porque la cultura andina es una cultura sincrética, en cuanto que toda su historia está hecha de elementos culturales que incorpora de las otras culturas, modificando aspectos significativos de su propia cultura original.

La misma cultura Inca no se puede entender sin la lógica de la piedra y del mismo dios creador Wiracocha, traídas de la desaparecida cultura Tiahuanaco; sin los elementos de la lógica de las sociedades hidráulicas costeñas de los Chimú y Mochica, sin la lógica del oro y de la jerarquía de los Chimú, etc.

Así tampoco se puede entender la cultura andina actual sin la lógica de la cultura occidental antigua y nueva. La antigua como el de la culpa por cometer pecados y el de limpiarse de la misma a través de la adoración de la virgen y de los santos o la cultura occidental actual de la valoración de la tecnología automática y relacionada con el mercado y de la lógica las otras culturas que han tenido una cercanía con las culturas andinas, como la cultura africana expresada en las máscaras y comidas andinas.

La cultura andina del pasado es transformada en interacción con las otras culturas y tiene una transformación que es necesario precisar.

\section{b) La visión andina actual}

- El agua es un ser vivo

Si seguimos el gráfico 1 , se puede observa que el agua es un ser vivo en sí misma, aunque también proveedora de vida y de animación al universo, sin que ello signifique que no se le trate, también, como un insumo para generar productos para el mercado.

Como ser vivo se le cuida, se le trata con cariño, se le conversa y se le cría para que esté a favor de los seres humanos y de todos los seres. Sin embargo, también puede ser un recurso natural mercantil, cuando se produce algunos productos que están directamente vinculados con el mercado. Este el caso de la papa que se produce para el mercado, que no se la cuida porque se le echa químicos a la tierra, como la úrea y se busca que esté artificialmente grande, combinándola con los demás fertilizantes, y también cuando los cultivos crecen, se les pone insecticidas para que sean vendibles en el mercado, Esta tierra con el agua viva, solo puede ser justificable producirla, con el agua de riego, que produce dos o más cosechas al año, satisfaciendo las demandas del mercado y de la creciente población comunal y de las ciudades.

Sin embargo, existen otras papas que no son para el mercado, sino para el consumo doméstico que no necesariamente tienen que tener riego y que se les cuida, son netamente como seres vivos, usando solo el abono natural y que aún no siendo grandes, son más nutritivas y palatales. La corriente mundial ecologista que rescata lo orgánico podría ser aceptada con mayor 
adaptación, por la cultura andina, y no solo ello sino que lo haría con creces porque, al ver el agua como un ser vivo puede aceptar la visión de lo puramente orgánico de dicha corriente.

Aun así, la papa, para el mercado, se ha incorporado como parte de la cultura andina porque a los andinos les interesa tener dinero para su educación, alimentación, el consumo de algunos productos industriales, techos fabricados y otros. Últimamente se está valorando en el mercado a la papa nativa y orgánica, lo que hace que la forma cómo se cultivaba la papa para uso doméstico, también se extienda hacia el mercado.

- El agua es un ser divino

En la visión andina original del agua se concibe que ella no es solo un elemento vivo sino místico, porque el dios creador y los dioses también están presentes en el agua, por tanto vigilan el comportamiento de los seres humanos. Desde esta visión, es necesario que la comunidad mantenga contento a los dioses y una de las maneras más típicas de hacerlo es a través del pago al agua, construyendo diversos rituales, que aun teniendo ciertos componentes comunes en todo el ande, varían en todo el ande.

Lo común de los rituales, es que al inicio del proceso, previo a la siembra, se requiere que toda la comunidad con sus invitados, se reúna y realice una especie de peregrinaje desde el centro poblado hasta la fuente de agua, procurando que a través de una peregrinación, los comuneros realicen diversas demostraciones artísticas y folklóricas con la participación de todos los componentes de la comunidad, mujeres, niños, adultos y jóvenes, como generando una energía que predisponga a que la ceremonia se lleve a cabo con toda su plenitud. Los peregrinos siguen al jefe de la ceremonia que es el comunero más antiguo y reconocido de la comunidad, quién es el encargado de efectuar la ceremonia, acompañados por los músicos del pueblo, donde no falta la tinya y el tambor.

Habiendo llegado a la fuente del agua, tanto los comuneros jóvenes, las autoridades y algunos invitados, se disponen hacer la limpieza del canal o de la acequia que conduce el agua a las parcelas. Inmediatamente, el jefe busca un lugar clave simbólico donde nace el agua que vendría a ser el punto de unidad con la divinidad. Y en dicho lugar efectúa el pago el agua, que consiste en echar hojas de coca, licores diversos, cigarrillos y otros elementos muy preciados por los comuneros como señal de entrega, como un regalo, como un acto de subordinación y pedido para que venga el agua y nunca falte. Después de este acto, el personaje de la comunidad que comanda la comitiva que hace el pago el agua, dirige una oración y una alocución, pidiendo que sea un año bueno, donde la comunidad se beneficie del favor de los dioses y seres divinos que se encuentran tanto en el agua como en los cerros y en todo el universo. En la visión andina del agua, este no es un elemento aislado del universo, está concatenado con todos los otros componentes de la naturaleza, los cuales están unidos bajo el hilo de la divinidad.

Finalmente, se hace la limpieza de la 
acequia o canal cercano y la comunidad organiza una fiesta

Este ritual varía según las diferentes culturas regionales y dentro de ellas los distritos y comunidades. Por ejemplo, en el II Encuentro de Comisiones de Regantes de la Región Ayacuho”, acaecido en el distrito de Aucará de la Provincia de Lunacas, una delegación de la Universidad Nacional Agraria La Molina, comandada por el actual rector, Dr. Abel Mejía Marcacuzco, originario de dicho distrito y comunidad al mismo tiempo, asistimos el 16 de Septiembre del 2008, a un pago al agua, donde el ritual estaba animado en todo su recorrido por los danzantes de tijeras, de todas las edades, y tuvo como singularidad hacer primero un pago a la tierra, combinado con un pago al agua con la animación de una banda de músicos.

No se sustituía a los clásicos instrumentos de origen ancestral andino como la tinya y el tambor sino que paralelamente actuaban las dos clases de músicos. Así también, quién comandó el ritual fue efectivamente uno de los más antiguos, que habían pasado por todos los cargos e incluso se consideraba como el paco o shaman mayor de la comunidad. En cambio, en el 2010, se tuvo la oportunidad de visitar a las comunidades de altura de la cuenca del río Lurín, de la provincia de Hurochiri de la provincia de Lima.

A las comunidades de Santiago de Tuna, San Andrés de Tupicocha y San Damián. En estas comunidades con mayor influencia de la cultura criollo occidental debido a la cercanía y gran intercambio con la ciudad de Lima. Se encontró que en la comunidad de San Damíán, si bien, el pago al agua es vigente y muy intenso, la banda si ha sustituido a los instrumentos clásicos y el que dirige el ritual, no es necesariamente el comunero más antiguo de la comunidad sino el más reconocido por sus capacidades y habilidades personales y su compromiso con la comunidad.

Si bien, el ritual varía según las culturas regionales, la articulación con la sociedad mayor y las circunstancias se mantiene el fondo del mismo, pagar al agua para que este ser divino corresponda a las demandas de la comunidad, consistentes en tener agua fluida, voluminosa y complaciente..

- El agua articula el universo porque se encuentra en todos los seres y los integra

El agua se esparce por todo el universo y sirve para unir todos los seres, cuando ingresa en la tierra, la hace fertilizar, potenciando todos los elementos orgánicos que contiene y los interrelaciona; asimismo cuando ingresa en el ser humano mismo, permite que todos los elementos del cuerpo humano se unan y funcionen en el organismo humano.

Así también une al cielo y la tierra y por tanto es divina, cuando el hombre se congenia con los cerros y los seres divinos se comunican con los componentes del cielo y llueve, cuando se piensa que en las noches las estrellas bajan a bañarse en los pukyos y desde ellos así como de las lagunas, parten los arcos iris que van a terminar en el cielo, tal como nos lo revela la investigación, realizada en Cajamarca, por Ana de la Torre.

Los estudios de Juan Ossio son muy 
importantes para esclarecer este rol del agua al señalar que el agua es concebida como un semen que se esparce en la tierra para fertilizarla.

Así también los estudios de José María Arguedas, cuando observa que para el andino el agua es como la sangre que permite activar las funciones del Universo, que de alguna manera lo expresa en sus libros "Agua" y "Los Ríos Profundos". Es una agua dinámica, sumamente torrentosa, que comunica vigor y entereza, que circula y hace que la gente se vuelva generosa, así como lo es la corriente de agua que se entrega al resto del universo.

- El agua como todos los seres vivos tiene dos lados unidos, lo bueno y lo malo El agua cumple un rol positivo en el universo al fertilizar la tierra y unir a todos los seres, aunque también cumple un papel negativo cuando se convierte en huayco, en deslizamiento o alud, escaseando o helándose hasta matar a la planta. Así se comporta el agua, cuando castiga ante las faltas del hombre o de la comunidad; en este aspecto si se ha fundido con el dios castigador de la religión católica medieval que trajeron los españoles, que creaba la culpa. Sin embargo, esa misma agua, bien tratada con los pagos y los demás ritos del agua, puede convertirse en buena nuevamente y cumplir un rol positivo.

En este aspecto la cultura andina ancestral no ha podido fundirse con la cultura occidental, la cual, ve a la realidad como dual y separada, lo bueno está separado de lo malo, son dos elementos opuestos, lo bueno no puede ser malo a la vez, ni pueden estar en una misma persona o recurso natural. Más bien coincide con la cultura oriental donde no existe dualidad sino unión, ambas culturas reconocen los dos aspectos unidos indesligablemente, uno no puede estar sin el otro.

Por ello, en la cultura andina, el diablo que es el que peca e infringe las normas morales y por ello mira de un lado a la virgen, es a la vez protector, proporciona seguridad a los hombres y mujeres. Así también, contenta a los seres humanos teniendo muy buen humor y sentido de cooperación, cuando se calienta azota a los que violan las normas de la comunidad y es sumamente celoso del orden aunque esté mezclado con la alegría y la hilaridad. En otras palabras el agua es benéfica porque permite la vida de los seres humanos, las plantas y los animales pero al mismo tiempo es maléfica porque con ella sobrevienen los huaicos, heladas e inundaciones.

- El agua integra a los seres humanos y los vuelve unidos a través de las comunidades mediante la reciprocidad, todos merecen estar unidos a los seres divinos que se encuentran en los cerros, en los lagos, en los cielos.

La distribución del agua, el mantenimiento de la infraestructura y las operaciones que se hacen para habilitar el agua $y$ hacerla accesible a los hombres, supone la existencia previa de la comunidad y de las relaciones sociales entre los comuneros. De hecho para que todos se sientan unidos a un territorio, que contiene fundamentalmente agua, a fin de que los seres humanos se sirvan de ella en forma organizada, a través de la reciprocidad.

Gelles señala que el andino ve a la tierra como una raíz en medio de un inmenso 
territorio de agua. Este territorio tiene sentido cuando pertenece a una comunidad de seres unidos por un mismo destino de reciprocidad y cooperación. La reciprocidad es la comunidad, el agua se otorga, porque los miembros de la comunidad o del caserío han trabajado, sino no tiene sentido entregarla, así se haya pagado dinero. El trabajo se realiza en comunidad frente a un ande tan rico y difícil como el que describimos anteriormente. Esta vinculación del agua con trabajo, es uno de los elementos para explicar la falta de pago monetario, en las actuales organizaciones del agua, traídas o jaladas de la costa, que exigen solo dinero.

Este dinero, en último caso, puede sustituirse por bienes y mejor por trabajo. En la cultura andina, con bienes es el menor mal, a fin de vivir de acuerdo a los nuevos parámetros del progreso, que exigen alcanzar mayores niveles educativos, trabajar en empresas y adquirir una posición de poder (un cargo) importante en la sociedad. El hecho de crear una junta, comisión o comité de regantes, sin que haya habido antes una comunidad no tiene sentido entre seres que no se conocen, ni se sienten unidos entre sí por un destino común.

Es por ello, que las comunidades asumen las juntas de usuarios y sobre todo las comisiones de regantes, como si estas fueran parte de sus comunidades, estas son el hilo conductor de aquellas y están detrás de las juntas o comisiones. Haciendo convivir los nuevos cargos del progreso y la modernidad con cargos tradicionales, tal como nos lo dijeron los profesionales y técnicos del ITDG, en el taller organizado por el GPER Inka, del 6 al 7 de Febrero del año 2,003, quienes trabajan con los campesinos de la comunidad de Livincaya de la provincia de Canchis en el distrito de Sicuani, señalándonos que la comisión de regantes ha sido aceptada aunque no la junta de usuarios y que los cargos tradicionales de tomero y teniente auxiliar continúan y que la comisión actúa cumpliendo sus funciones básicas, previstas por el Estado, con eficiencia, incluyendo los ritos y las costumbres andinas del agua.

Así, lo pudimos ver en Huánuco, un grupo de profesores de la agraria (Agosto del 2008), coordinados por el CEPID, en coordinación con la municipalidad, en las comunidades de Santa María del Valle, donde los cargos de la comisión de regantes y sobre todo de los comités de regantes eran elegidos, promovidos y supervigilados por la comunidad. La comunidad es la animadora y garante de todo el sistema de producción y distribución del agua, como vamos a ver más adelante. Así también en las partes altas de la microcuenca del canal Sedamal El Toro en Celendín Cajamarca, han aceptado una comisión de regantes y diversos comités de regantes que funcionan como comunidad, haciendo faenas para reparar la infraestructura del canal, cuidando que los regantes formales de abajo no vengan a quitarles lo que informalmente usufructúan. Una versión amplia de este caso se examina en el libro sobre conflictos y gestión que escribimos últimamente.

- La gestión del agua es flexible y adaptativa porque el agua misma se contornea y circula confundiéndose con 
los vericuetos de la naturaleza que es diversa y accidentada

El agua se desenvuelve en forma natural de una manera flexible y se adapta a las circunstancias y esta manera al actuar sobre la tierra, refleja también el comportamiento de los hombres que están continuamente observando las circunstancias y los elementos que vienen de afuera y con flexibilidad, los asimilan y redefinen, según sus propias necesidades, correlaciones de fuerza y creencias. La mentalidad andina es profundamente metafórica, en cuanto observa la naturaleza y extrae la esencia de sus movimientos y realiza equivalencias con sus propios comportamientos humanos.

Tal como lo plantea Javier Solís en el taller de "Visión Andina del Agua" organizado por el GPER INKA junto con el CIED, en diciembre del 2006, el sistema organizativo andino es notablemente flexible, su gestión varía según las circunstancias y coyunturas. Si bien es cierto, tienen normas y parámetros, logrando consensos, producto de acuerdos comunales, pueden cambiar hasta sus cédulas de cultivo, ante la presencia de sequías, abundancia de agua u otra emergencia.

Así también asimila prácticas y técnicas de otras culturas con relativa facilidad y adaptación, lo que la hace sumamente cambiante en sus actividades y pensamientos y la prepara para desarrollar actitudes favorables a la interculturalidad o convergencia, consciente y planificada con los otras culturas.

Evidentemente, estas actitudes, a nuestro entender, son las más importantes de las cinco que señala Solís, porque generan las otras tres. Es decir si los andinos son flexibles en su gestión y por ello rotan sus cargos, alternan el reparto de agua entre los de arriba y los de abajo con un criterio de reciprocidad y delegan responsabilidades entre los miembros de la comunidad sean hombres, mujeres o niños, así también pueden desarrollar otras actitudes como el respeto, la afectuosidad y la eficiencia.

- Los derechos de agua están basados en sus costumbres y tradiciones, no en una imposición de afuera hacia dentro, examinando la forma de llevarlas a cabo en forma flexible, sin negar necesariamente al Estado Nacional

Los derechos de agua están establecidos ancestralmente a partir de la conciencia y experiencia de la organización social del agua, en cuanto que los recursos naturales pertenecen a todos y todos tienen derecho a disfrutarla en forma organizada, a través de la comunidad y también se tiene el deber de cuidarla, encariñarla, incluyendo a todos los seres que están relacionados con ella. Sin embargo, al pertenecer también al Estado nacional, se tiene en cuenta sus dispositivos, para llegar una amalgama que responda a ambos intereses.

Las conclusiones del taller "Visión Andina del Agua" enfatiza que la sociedad andina se organiza en la equidad por medio de la colectividad y que la legislación es básicamente comercial.

Sin embargo, nosotros añadiríamos que ambas posiciones pueden amalgamarse y lo hacen en la práctica, tal es el caso del ejemplo de la papa, que se ha dado 
anteriormente. Este es el profundo sentido de la interculturalidad, se percibe las diferencias para efectivizar posibles convergencias y creadoramente se combina algunos elementos diferenciados procedentes de distintas culturas, convirtiendo aquellas diferencias en complementarias. En el video y en el texto "Pacha Mama Raymi y "Pachamama Urupa” promovidos por el PRODERM en la década de los ochenta y MARENAS en las décadas de los 90 hasta los primeros años del siglo 21, se observa que en los concursos que organizaba el PRODERM del Cusco, junto con las comunidades y que actualmente siguen haciéndolo diversos proyectos como MARENAS, PRONAMACHCS y otros: Se amalgamaba la fiesta andina con el diseño de los surcos en contorno, de procedencia occidental o las acequias con compuertas de procedencia occidental o la tradición andina de trabajar con música haciendo uso de un equipo de música.

Como señala Boelens en Derechos de Agua y Acción Colectiva, IEP, 2001 y en sus diferentes trabajos, los derechos de agua establecen los siguientes aspectos: quiénes cuentan con el derecho del uso del agua y de la infraestructura hidráulica; cuáles son las condiciones para ejercer dichos derechos; cómo y cuándo a un usuario del agua le es permitido recibirla; cuál es el costo del uso del agua, igual a todos sin distinción alguna, y cómo les es permitido a los usuarios participar en las decisiones colectivas del uso del agua.

Como el mismo Boelens sostiene que cuando es el Estado el que funciona como normador y supervisor y los usuarios como canalizadores de los derechos que les parecen claros. Al contrario, cuando estas normas estatales y atribuciones de los usuarios, se superponen con los

\section{Gráfico 1: COMPONENTES DE LA VISIÓN ANDINA DEL AGUA}

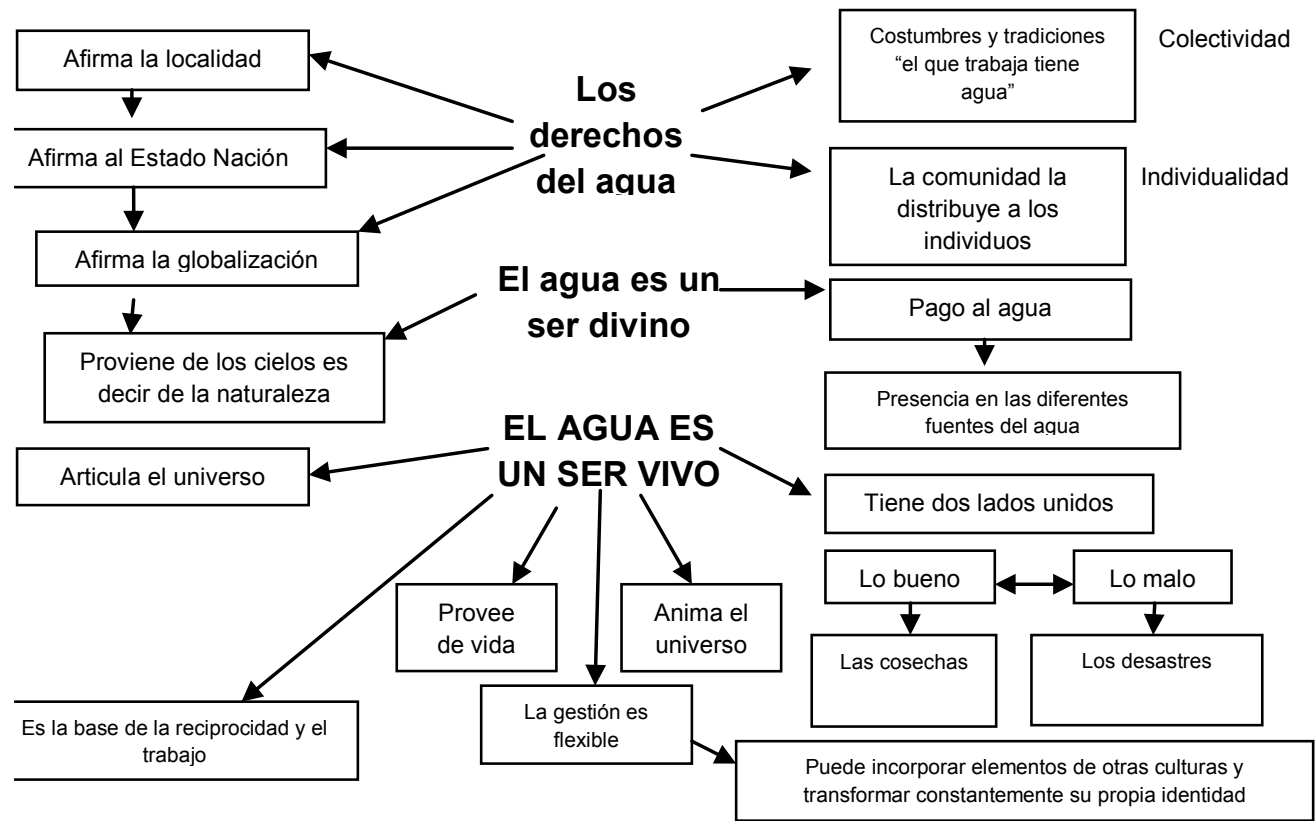


derechos consuetudinarios de los andinos, la cuestión se vuelve problemática. En este caso es el mismo Estado, el que debe considerar la particularidad de la sociedad, donde ejerce el derecho, aceptando diversos componentes del derecho consuetudinario. La interculturalidad también puede ser estimulada desde la iniciativa del Estado y las ONG.

Tradicionalmente, los derechos del agua los impusieron primero los hacendados y después el Estado, intentando subordinar los derechos tradicionales de los usuarios andinos, sin mayor esfuerzo ni éxito.

La visión andina tal como lo señalan los resultados de dicho taller, por el grupo 4, tienen como fines la equidad y por tanto la accesibilidad colectiva del agua a favor de los regantes, según su aporte en el trabajo y su pertenencia a la comunidad. Por tanto, la compensación por su uso está muy relacionada a la reciprocidad en el trabajo, al cumplimiento de las responsabilidades a través de los cargos y de las cuotas (dinero) de acuerdo a los gastos reales y eventuales, por último a la retribución en especie.

En cambio la legislación estatal tiene como fines: ponerla a disposición privada para operaciones comerciales y distribuir racionalmente el agua. Y su compensación se concreta a través de tarifas fijas pagables en forma monetaria. El derecho consuetudinario y la legislación estatal se superponen. Es necesario que haya una conciliación y sobre todo convergencia, manteniendo aspectos básicos del derecho consuetudinario y algunos elementos comunes que no afecten en lo sustancial al derecho estatal.
Como habíamos señalado la cultura andina del agua no opone sus derechos a los que establece el Estado, intenta hacer una amalgama, aunque requiere de la voluntad colectiva del Estado y la sociedad mayor para lograr este empate. Recién los últimos años se abren canales para una reconciliación.

La última reforma constitucional, respecto a los cambios de la constitución de 1993, formulada por una comisión del congreso y publicada por la Dirección de Cultura del mismo en el 2,002, considera en su artículo 2 "...que los pueblos indígenas que tienen derechos anteriores a la formación del Estado, mantienen una cultura propia, un espacio territorial y se autoreconocen como tales..." Y en el artículo 5 inciso 4 acepta "la propiedad de los territorios que ocupan y de los recursos naturales tradicionalmente utilizados en sus actividades en armonía con su preservación y adecuado uso.

Tienen autonomía en el control, uso racional y administración..." $\quad Y \quad$ si agregamos algunos artículos de la nueva ley de recursos hídricos aprobada y promulgada en el 2009, en su artículo 32 reconoce que "... las comunidades campesinas y comunidades nativas se organizan en torno a sus fuentes naturales, microcuencas y subcuencas de acuerdo a sus usos y costumbres...". Basado en este artículo promueve la mejora en la gestión del agua. La autoridad de agua otorgará las correspondientes concesiones con arreglo a esta ley. Estos últimos dispositivos otorgan un espacio al derecho de agua indígena, 
teniendo en cuenta sus tradiciones aunque sin negar su derecho a integrarse a la estructura del Estado, tal como parece ser la voluntad colectiva de los usuarios andinos, al aceptar muchos comités y comisiones de regantes. Según Javier Solís, en la ponencia mencionada, sostiene que los derechos de agua fundamentales deberán ser reconocidos por el Estado. Se encuentran en vigencia en los pueblos indígenas, es decir al uso directo del agua, al uso de los canales y a la toma de decisiones en las instancias colectivas correspondientes. A esta apertura se agrega los derechos aceptados por los propios indígenas, los cuales se basan en tener propiedades, aportar en las faenas de limpieza y asumir los cargos religiosos y civiles.

Es decir, cumplir obligaciones como son las faenas y los cargos, ser sujeto de sanciones mediante amonestaciones, como por ejemplo otorgar los turnos al final o no darles agua, ser reconocidos por el colectivo al trabajar por el sistema de riego y poder organizar las faenas y obtener el beneficio de un turno de riego y participar en la toma de decisiones para la gestión del sistema.

Como vamos a ver más adelante, la realidad cultural del país es muy diversa, por tanto, no se puede uniformar el aparato normativo de los regantes, salvo en algunas normas genéricas y sintéticas. La normatividad detallada mediante reglamentos deberá surgir de la realidad física y cultural de cada microcuenca.

4. Las diversas visiones andinas del agua En medio de la unidad también existe una diversidad de visiones andinas del agua que se han venido generando desde la época prehispánica, colonial, republicana I y republicana II. En la época prehispánica, incluso inmediatamente antes de las conquistas incaicas, hubo culturas muy diferenciadas, solo nombraremos algunos casos como son: la cultura Huanca que adoraba al perro, donde lo hidráulico no era significativamente tan importante, ante el imponente valle del río Mantaro, el cual, los huancas controlaban y disponían de abundante agua. . La cultura Chimú que fue fundamentalmente hidráulica, cuya adoración al agua era notable al no tener agua en sus costas; la cultura Chanca fundamentalmente guerrera $y$ de conquistas, basadas en el agua de los lagos, aunque con uso eventual, ante la movilidad de su población, que buscaba siempre nuevos recursos afuera mediante la guerra. La misma conquista se explica por la alianza entre los españoles con las culturas conquistadas por los incas, las cuales, colaboraron con ellos.

En la época colonial los ayllus se convirtieron en comunidades campesinas a la usanza española, reduciendo al máximo el control del espacio y del agua hacia territorios de menor dimensión, provocando competencia entre comunidades, bajo el principio de "divide y reinarás" sobre la base del control del agua. En la época republicana I (18211950) antes de la creación de las grandes ciudades, del aparato del Estado liberal y de las migraciones andinas, el sistema de hacienda controlaba el agua y la que quedaba la repartía desigualmente entre las comunidades provocando también competencia y fraccionamiento. En la época Republicana II (1950-2010), el 
Estado le quita el control del agua a las haciendas y promueve la organización dependiente de los regantes, los andinos migran hacia las ciudades y comienzan a controlar en forma modesta y paulatina, tanto al campo como a la ciudad a través de una invasión silenciosa, tal como sustentó Matos Mar es su texto sobre Desborde Popular 1984 IEP. Solo un sector de las comunidades campesinas andinas prescinde parcialmente del Estado, cuyo interés por incorporarlas ha sido precario $\mathrm{El}$ resto de pueblos andinos que no son comunidades, se integraron al sistema estatal formando juntas de usuarios, comisiones de regantes y comités de regantes. Incluso un sector importante de comunidades se ha incorporado a través de relaciones interculturales a la estructura organizativa estatal.

Solo desde la década de los noventa se quiso romper este control estatal sin efectivizarlo completamente, al quedar pendiente para una nueva ley de aguas que le diera mayor importancia a la autonomía de los regantes, a la organización de espacios mayores en el ámbito de cuenca y la eficiencia en el uso del agua, consolidando los derechos y licencias del agua.

Estas visiones no se han constituido sobre matices o elementos secundarios, sino tienen que ver con temáticas sustanciales como el orden de importancia del agua, dentro del universo andino, la misma forma de concebir el agua; la diferente organización para la colocación de la infraestructura hidráulica y la diversificación de las tareas en la distribución de la misma agua en tipos comunidades campesinas, caseríos, rondas, etc. Hemos detectado variables diferenciadoras que es muy importante captar para entender esta diversidad.

\section{a) Pisos ecológicos}

Es cada vez más evidente que existen importantes variaciones en las sociedades andinas según el piso ecológico en las que se ubiquen; cada piso les ofrece retos ambientales diferentes: Es decir, un distinto volumen y calidad del agua, tipo de suelos y cultivos y recursos naturales en general, en medio de diferentes climas y microclimas, morfología de la tierra, tipo de desastres y una biodiversidad bastante diferenciada.

Lo que supone que las sociedades tienen que organizarse para enfrentar estos retos y responder al medio, de tal manera que puedan tener una calidad de vida digna en las condiciones contextuales regionales y nacionales en que se encuentren.

Es por ello, que es poco preciso hablar de las sociedades y medios físicos andinos sin referirse a cómo ellas están enfrentando las condiciones que les ofrecen los pisos ecológicos y los lugares del espacio de las cuencas en que se encuentran dichas sociedades.

En el piso Chala, el agua no existe, solo se presta de los otros pisos más altos. Por ello, las sociedades han tenido que organizar un fino sistema de generación y reparto del agua, cuya fortaleza hasta la actualidad se puede observar. En cambio, en el piso más inmediatamente alto, la yunga, el agua no solo escasea sino se distribuye en montańas muy empinadas y escabrosas, que hacen difícil la vida humana; por ello existe una despoblación de este piso, porque 
ni siquiera los ritos logran atraer el agua. En cambio en el piso superior, llamado quechua, el agua, si se encuentra con ricos valles interandinos y la sociedad tiende a organizarse no solo con comunidades sino con activos municipios provinciales y distritales, algunos de ellos como cabezas de gobiernos regionales. En los pisos más altos, se hace más difícil el agua porque vuelve a ser demasiada montañosa y fría, que solo en las mesetas más altas da lugar, en la puna, a una creciente población animal (ovinos, vacunos, auquénidos).

La ubicación en los pisos y las partes de las cuencas (alta, media o baja) son como el suelo donde se cultivan las plantas, ponen las potencialidades o límites que pueden ser aprovechadas o desaprovechadas por las sociedades humanas.

Es por ello que es necesario que se relacione los pisos con ciertas variables sociales básicas, como las generaciones que hacen variar también las visiones andinas del agua según la juventud o adultez de los grupos humanos.

Así también el género, en la medida que existe una forma particular de ver las cosas por parte de los grupos e individuos de los diferentes sexos; asimismo, las sociedades andinas se han diferenciado según las culturas y subculturas que han constituido a través de su experiencia histórica y a la mayor o menor incorporación o convergencia que han tenido con la cultura occidental, inicialmente traída por los españoles, y después por los italianos, alemanes, franceses y americanos.

Por último, el tipo de organización andina influye en la visión andina del agua porque es la que más cerca tienen los habitantes andinos. Cada organización se diferencia de las otras según el piso ecológico, en que se encuentre. Los andinos en el piso Yunga, caracterizado por la escasez, tienen una organización muy precaria y operativa, que les permita migrar periódicamente al piso quechua; en cambio en el piso quechua, fortalecen su organización debido a la cercanía al mercado y a las ciudades interandinas. En el suni establecen una organización fuerte, que controle el buen uso de los recursos naturales, muy escasos en este piso y sumamente riesgosos, por lo que prefieren elegir líderes creativos y de gran legitimidad.

En cambio, en la puna y la jalca, su organización vuelve a ser operativa $y$ muy puntual, debido a la ausencia de los ganaderos que se encuentran pastoreando a grandes distancias. Esto se refleja en el cuidado del agua, que es muy elemental en el piso yunga, muy fina y modernizada en el quechua, muy racional en el suni y un tanto flexible en la puna y la jalca.

\section{b) Generaciones}

Una segunda forma como varía la cultura del agua es por la existencia de diferentes generaciones y géneros, como lo vemos en el Gráfico 2. Es de destacar las enormes diferencias, por razones generacionales, que se están presentando en el área andina. Los niños andinos desde comienzos de la República II tienen mayor opción para recibir y recrear los contenidos de la cultura criollo-occidental, al haber una escuela oficial no bilingüe y los medios de comunicación, como la radio presentan modelos culturales distintos. Solo en los últimos años se nota un regreso más activo 
de la visión del mundo andino. No creo que todo se reduzca a considerar a que los niños sigan al modelo de los padres y jueguen tal como concluye el taller.

En cambio, los jóvenes si están teniendo un cambio significativo en la visión andina del agua. En 90 entrevistas testimoniales que hicimos en una investigación sobre la relación sobre las actitudes de los andinos ante sus recursos culturales en los años 1987-1988, concluimos que la generación joven en distintos departamentos especialmente en los pisos ecológicos puna y quechua valle, con mayor relación con la ciudad y el mercado, los jóvenes se distancian de los ritos al pago al agua y a la tierra, al examinar el agua sólo como un recurso mercantil y útil y habían hecho un sincretismo mayor con la cultura occidental.

El taller realizado reconoce que los jóvenes están en un proceso de transculturación. Esto no necesariamente significa que se abandone la cultura andina, esta se recrea mejor con nuevas versiones de la cultura occidental más reciente que valora la ecología, el naturalismo y la diferenciación de las culturas, mostrando interés en la interculturalidad.

En cambio los adultos sobre todo en el piso Puna se apegan a sus tradiciones, en quienes la visión andina ancestral, tiene menos transformaciones, al tener un contacto eventual con las ciudades.

En dicho piso el agua es importante en tanto alimento para el ganado y en cuanto están más expuestos a las heladas fulminantes en los pocos cultivos que soportan dicho piso. De allí que los ritos del agua son muy importantes en especial en las partes altas de la cuenca, donde existen lagos y lagunas en dimensiones significativas que provocan mayor imaginación en medio de la soledad, en que se encuentran los miembros de este piso, donde el pastoreo y las estancias alejan a los unos de los otros.

En los pisos yunga y suni, donde el agua es escasa, se hace un esfuerzo sobrehumano por sobrevivir, demandando al Estado una infraestructura de riego, con pocos resultados, están en proceso de despoblación, teniendo que reducir las faenas y los actos rituales para que sean llevados a cabo por pocas personas: La visión andina, de este modo, está entrando en crisis.

En cambio en el piso quechua valle con mayor influencia de la ciudad hace que los adultos muy dependientes de los medios de comunicación como la radio y la televisión parabólica y la institucionalidad de la sociedad civil y política, en especial en estos años de lucha contra la pobreza, tiene que abrirse para recibir ayuda, los mismos ritos y pagos, aun conservándose, van alterando sus contenidos. Son patéticos los cambios de contenido de la peregrinación Qoylluriti del Cusco, donde el máximo acto ritual es llevar los hielos a las cumbres de los nevados y cerros y bajar para hacer actos simbólicos de reciprocidad en la entrega de productos. Ahora se entregan dólares simbólicos, camiones y computadoras.

Este mismo fenómeno sucede en menores dimensiones en el piso quechua laderas, aunque también tiene importancia, 
la generación de adultos no deja las costumbres, las alteran en sus contenidos. Existe todavía un fuerte sector de adultos y ancianos, sobre todo en este piso ecológico, que se apega a las costumbres y trata de mantenerlas aunque la despoblación también se presenta en este piso, teniendo que disminuir las faenas y ritos. Solo la posibilidad de tener una agricultura de riego y de contar con una agua no contaminada los alienta a mantenerse interesados en la visión andina del agua.

\section{c) Género}

En los resultados del taller se observa que esta variable no tiene importancia para diferenciar la visión andina del agua porque tanto los hombres y mujeres tienen las mismas oportunidades y responsabilidades en una relación de reciprocidad, diálogo y equidad. Sin embargo en la cultura andina, tal como lo constatan Escalante y Valderrama, 1988, se asocia al agua con lo femenino, en forma indistinta según su ubicación. Si se trata del agua de los cerros, a los apus, que se encuentran en ellos y los nevados, son seres rudos y fuertes y se les trata como masculinos. En cambio, son femeninos, cuando se trata del mar y las lagunas.

$\mathrm{Si}$ se trata de ventilar las relaciones de intercambio, el agua es masculina porque es el semen de la tierra y la última es femenina que lo recepciona y lo fecunda. Así también, Ana de la Torre en un trabajo ya citado, señalaba que los pukyus, las paqcha o caídas del agua, las qochas o lagunas más pequeñas y ríos son femeninos.

Esta cultura del agua se refleja en las divisiones de trabajo por sexo; los hombres realizan las tareas con relación a la gestión del agua, se les responsabiliza en la construcción de infraestructura para el agua potable, riego y en labores pesadas de esta actividad, tal como lo reconoce Ricardo Claverías en su texto sobre Género e Interculturalidad CIED-Agualtiplano, son los hombres los que asumen este

\section{Gráfico 2: VARIABILIDAD DE LA VISIÓN ANDINA DEL}

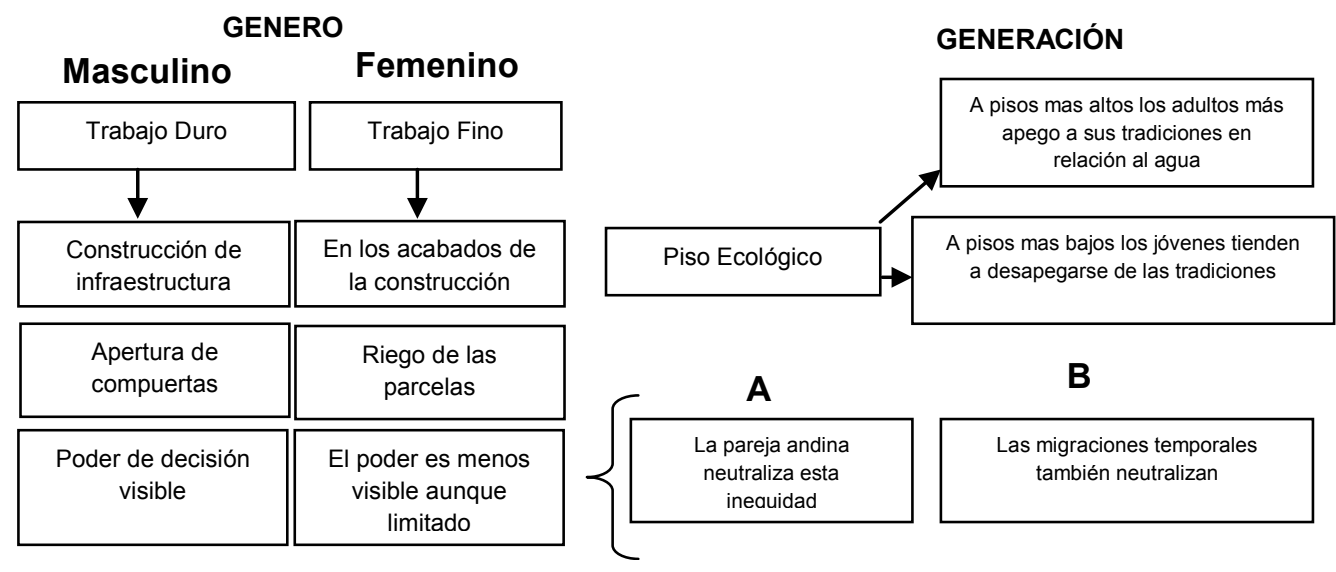


trabajo. En cambio, las mujeres intervienen en las labores más finas y complementarias en la construcción, que muchas veces deciden la eficiencia del riego.

Esto se reproduce en el riego donde para la apertura de compuertas y las actividades de distribución del agua se suele responsabilizar a los hombres y a las mujeres en el riego de las parcelas, que requiere más cuidado y fineza, como parte de las habilidades propias de las mujeres, donde los detalles definen los hechos más efectivos. $\mathrm{Al}$ igual el control tecnológico es más centrado más a los hombres que a las mujeres, por ello existe desigualdad en los niveles educativos, donde el analfabetismo es mayor en las mujeres que en los hombres.

En la misma cultura andina, Claverías reconoce que por esta distribución de diferentes responsabilidades se asocia a los hombres con las mayores oportunidades que tienen en la distribución de alimentos y en la dirección de las comunidades y en las organizaciones de regantes, produciéndose cierta inequidad. El mismo Claverías relativiza estas inequidad descrita, cuando señala que la importancia que la cultura andina, otorga a la pareja, hace que participen juntos en muchas actividades importantes, como el pago al agua y a la tierra, donde los elementos que se ofrecen, lo hacen por igual.

Nosotros añadiríamos que esta inequidad también se relativiza en las zonas de mayor migración eventual, cuando las mujeres asumen todos los roles y esto le resta importancia a los hombres, en la comunidad, empoderándose las mujeres de la cultura del agua ancestral, tal como sucede con mucha frecuencia en las comunidades de la sierra central.

En cambio, los hombres, incorporan los valores de cambio en la cultura andina, simbolizados en la entrega de camiones, dólares y computadoras en las ferias simbólicas. Como síntesis, consideramos que si bien es cierto existe la pareja que dialoga y asume en su conjunto las tareas de gestión del agua, con un sentido de reciprocidad y complementariedad, si se puede constatar inequidad cuando se trata de la toma de decisiones en los órganos de gobierno comunal y en los comités de regantes y en la distribución de bienes sociales y educativos que tienen incidencia en la menor cantidad de beneficios, que reciben las mujeres en la gestión del riego respecto de los hombres.

En resumen, la visión andina del agua de los hombres se relaciona con la gestión de los recursos naturales y las decisiones en los órganos correspondientes; y la visión de las mujeres, en el reparto equitativo y en la máxima sapiencia en que el agua llegue de forma uniforme a toda la parcela. Esto crea inequidad, la que ha provocado una reacción de las mujeres, que sin desconocer sus propias habilidades, pugnan por tener más oportunidades educativas y de ejercer las mayores funciones y los cargos en la gestión de los recursos como les corresponde.

\section{d) Culturas Regionales}

En el taller mencionado, como se observa en el Gráfico 3, las culturas andinas, indistintamente, conservan la visión mística del agua como ser vivo y divino, sin 
embargo, se ha detectado que las culturas regionales si influyen en el tipo de ritos y en las visiones del agua, según su cercanía al mercado y a las ciudades. En este sentido, en la cultura aimara, ubicada en la puna y en Puno, se hace los ritos sin tener que ver con la demanda de cultivos ni con el mercado y tampoco hace prácticas modernas occidentales del pago monetario, según grado exacto del consumo. En cambio, si se reconoce que en las culturas quechuas cuzqueńas, tanto en el piso quechua de laderas como del valle, si se están modernizando los ritos al agua y que los sofisticados ritos se producen cuando existe una mayor demanda de ciertos cultivos en el mercado.

La cultura aimara está ubicada en un piso ecológico donde abunda el agua y no se requiere mayor sofisticación en el uso racional del agua de acuerdo a una mayor exigencia del mercado. En cambio, las culturas quechuas ubicadas en pisos más bajos y con menor disposición de recursos hídricos, si están aceptando las prácticas y técnicas de procedencia occidental- que tienden a un uso más racional del agua, como es el caso del riego por aspersión, medición del agua de acuerdo a la demanda del cultivo, dosificación del uso. Sobre todo en ésta época cuando el agua se hace más escasa.

En realidad, el panorama es mucho más complejo y fino, teniendo en cuenta las diversas culturas regionales, los huancas, con mucho mayor pasado de comerciantes, desde la época prehispánica se relacionan, con mayor nitidez con la demanda de ciertos productos en el mercado y con la necesidad de racionalizar el uso del agua, por tanto, es para ellos muy común "el uso racional del agua", tildado como de procedencia occidental.

Los quechuas cusqueños del valle con una buena producción de maíz y una buena demanda internacional del mismo, han asociado, en forma estable y festiva, ciertos cultivos, con mayores precios, con la necesidad de hacer mayores pagos al agua. En cambio, las culturas tradicionalmente escasas en aguas y con poca influencia del mercado han sobredimensionado la necesidad de estar bien con los dioses y tienden a hacer mayores pagos al agua.

Fonseca y Mayer (Comunidad y Producción en la Cultura Andina, Fomciencias 1988) sostienen que en Casta existen 33 faenas anuales al agua con sus correspondientes rituales, desde la vertiente occidental, en cambio en Ucchuccamarca de la vertiente oriental solo realiza cinco. Este cambio en el número de faenas anuales y ritos del agua depende mucho del lugar que se ubican las culturas andinas. Si se ubican en la vertiente occidental endémicamente carentes de agua, tienden a ser más insistentes en las fiestas del agua.

En cambio, en las culturas ubicadas en la vertiente oriental, con más agua, aunque sin tener abundancia, los ritos y faenas son más moderados, aunque importantes, como en el Norte del Perú, como en Cajamarca. Ambos señalan en el texto que el hecho que se articulen las comunidades al mercado y al sistema estatal organizativo del riego, no ha mermado su espíritu comunal, más bien lo ha reorientado a un cambio de cultivos, manteniendo las fiestas y ritos con un entusiasmo inusitado. 
Gráfico 3: VISION ANDINA Y CULTURAS REGIONALES

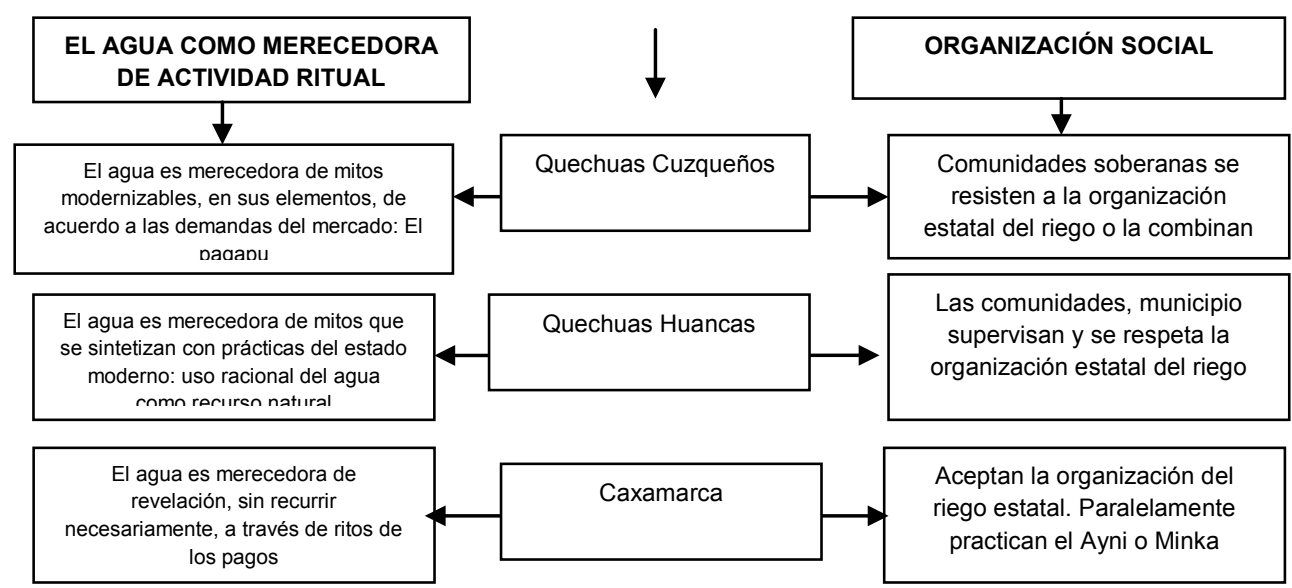

En síntesis si la organización y tradición comunal es fuerte, la comunidad al entrar al mercado, no necesariamente abandona todas sus costumbres ancestrales, más bien las reorienta y transforma constantemete.

A diferencia de otras culturas más débiles que son arrasadas por el mercado al tener contacto con ellas. Un caso analizado, como es el de Cañete y Yauyos, estudiado por Fonseca y Mayer, sostienen que no necesariamente las costumbres tradicionales se abandonan con el mercado, mas bien cuando ésta costumbres se amalgaman exitosamente se retroalimentan entre sí.

No existe necesariamente una oposición entre las formas tradicionales de trabajo del agua y las modernas: más bien sobre la base de las tradicionales y su transformación se impulsa mejor las relaciones de mercado hacia el progreso de los campesinos.

e) Organización andina del agua

Es indudable que existen en él ande diferentes organizaciones andinas del agua, desde las que han mantenido a la comu- nidad controlando las tareas del agua sin influencia estatal y las que han introducido el modelo estatal de comités y comisiones de regantes y las que han hecho una convergencia de ambas. Lo más fácil es señalar que la visión andina ancestral ha sido mantenida con mayor fuerza en las organizaciones comunales y con menor fuerza en donde existen las organizaciones, bajo el modelo estatal, como los caseríos del norte peruano. Sin embargo, esto no es necesario en todos los casos. Existen comunidades fuertes. donde a la vez que aceptan el modelo estatal de los comités como señalaban, Mayer y Fonseca, mantienen con fuerza prácticas ancestrales, aun articulándose mejor al mercado y reorientado sus cultivos como es caso de las comunidades de la cuenca del Cañete, estudiada por ellos.

Y existen comunidades débiles que aun sin modelo estatal organizativo, se van diluyendo las prácticas ancestrales ante conflictos internos y la migración y que finalmente su institucionalidad tiende a ser absorbida por la organización estatal. 
En el taller, se señala que en el piso de la puna en Puno, existen ciertas debilidades organizativas, derivadas de la abundancia de agua y de la vida pastoril. Sin embargo, en los pisos quechuas, especialmente en el quechua valle, se está aceptando el modelo estatal con cierto abandono de la visión andina del agua. Esta aseveración es relativa como cualquiera que se refiere al mundo andino. Depende de otros factores como la experiencia de identidad, capacidad de las comunidades para realizar equivalencias con respecto a sus organizaciones tradicionales, la presencia de líderes que no oponen lo tradicional con lo moderno y de la experiencia exitosa o fracasada de la combinación entre lo moderno y lo tradicional.

Un tema no considerado en el taller es la diferenciación organizativa entre el mundo andino comunal y no comunal. Existe un importante porcentaje de unidades organizativas andinas no comunales, llamadas, caseríos que abundan en la sierra norte del país y que en este aspecto se han incorporado a la cultura occidental moderna, adoptando la organización jurídico política del Estado.

Si bien se sostienen sobre la base de la reciprocidad, no se practican las faenas colectivas sino solamente a través de la ayuda mutua entre familias, llamadas minkas o ayni u otra denominación, según la región. Estas organizaciones no comunales han aceptado con más facilidad el modelo organizativo estatal, aun así mantienen mecanismos de reciprocidad y conservan la visión mística del agua.

En síntesis, el modelo organizacional que se ha fortalecido en cada una de las comunidades andinas, condiciona a que se conserve el sistema organizativo tradicional, se haya adaptado la modernidad occidental de las juntas y comisiones, o haya hecho una combinación entre ambas.

\section{Modernidad y visión andina del agua}

La modernidad en el uso del agua se basa en la aparición de las ciudades que demandan alimentos y agua potable. La presencia de la economía del mercado condiciona a la racionalidad en el actuar, con un criterio de eficiencia y distribución equitativa del agua, con igualdad de oportunidades para todos los ciudadanos. Esto conlleva la competencia con reglas del juego y la conservación de un sistema organizativo para su reproducción, como la organización de los regantes y el cuidado o mantenimiento de la infraestructura hidráulica.

Para tratar este tema, veremos tres puntos, cómo se valoran los aportes de diferentes culturas como la andina y la occidental y cómo en determinados aspectos pueden converger las dos culturas en función de mejorar la gestión del agua, llevando a cabo el proceso de interculturalidad en el uso del agua.

Empezaremos por la cuestión cultural, seguiremos con el Estado o el mercado y concluiremos relacionando las políticas del Estado y la visión andina del agua.

a) Interculturaridad y visión andina del agua

La interculturalidad. Como vemos en el Gráfico 4, se basa en el reconocimiento de que los valores y utilitarios tecnológicos de las diferentes culturas son posibles 
de converger. Es por ello que en el taller preguntamos qué se puede rescatar de la cultura andina y de la occidental. En éste se señaló que de la cultura andina se puede rescatar el pensamiento, reciprocidad, algunas técnicas tradicionales y ritualidad del agua y de la occidental algunos conocimientos y técnicas del uso del agua. Obviamente no necesariamente se oponen, podrían eventualmente complementarse. Asimismo, se examina si la visión integral de la cultura andina, que acepta al agua como parte de un todo coherente, no necesariamente se opone a examinar al agua en forma especializada. Los ecosistemas no niegan las partes sino las relacionan en un todo.

Al igual, la visión andina del agua que insiste en que el agua es un ser vivo y divino no se contraría necesariamente con la visión occidental del recurso natural, lo vivo siente aunque puede ser útil al venderse y obtenerse una ganancia. Evidentemente, no es ninguna gracia vender algún ser querido y con el que se ha hecho sintonía, sin embargo, por los menos para una parte de ese ser vivo, es posible aceptar esta nueva situación. Lo colectivo no necesariamente niega el sistema empresarial y privado hacia el mercado.

Asimismo la modernidad sacrifica el presente por un futuro ideal y de bienestar superior que muchas veces nunca llega, causando un estrés permanente y la visión andina se interesa en el presente y gozando de la relación personal y de la relación armónica con la naturaleza. Si bien es cierto, esta forma de modernidad del pasado si se

\section{Gráfico 4: POSIBILIDADES DE LA INTERCULTURALIDAD}

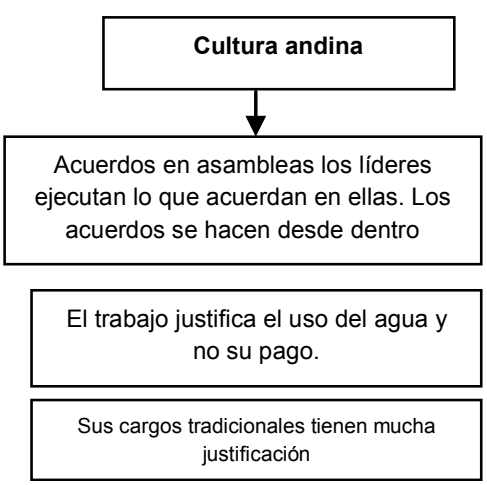

opone al goce del presente y a la cultura andina. Sin embargo, actualmente con la evolución de la modernidad hacia la postmodernidad, en ésta sí se goza del presente, coincidiendo con la cultura andina.

Además, el desarrollo sostenible es viable en la actualidad, a diferencia de las déca- das pasadas que se veía como una utopía. Ahora existe un mercado para los productos ecológicos, los productores ecológicos se organizan y todo el sistema se favorece cada vez más hacia una agricultura orgánica y la mejora de la calidad del agua, para el bienestar y la salud; así también se espera un Estado eficiente en los servicios públicos. 
Si bien el líder colectivo, propio de las comunidades, expresado en la importancia de las asambleas comunales y lo individual o lo privado como propio de la modernidad también podrían ser opuestos. Sin embargo, la evolución de las comunidades andinas hacia una mayor importancia de lo individual (parcelas y hatos de ganado individuales, herencia, familias, compromiso individuales con la comunidad, etc.), armonizándolo con lo colectivo, hace que esta contradicción no sea tan grande como se plantea. Existe la posibilidad de. la combinación de lo colectivo y lo individual con buenos resultados, dependiendo de las circunstancias y la voluntad colectiva de los actores sociales. Si no fuera así, cómo podríamos explicarnos la tendencia de los andinos a formar, empresas comunales, cuando éstas son promocionadas por el Estado en gobiernos tan diferentes como el dirigido por el General Juán Velasco Alvarado y del Ingeniero Alberto Fujimori. El primero promocionaba empresas comunales grandes y el segundo, quiso inicialmente hacer lo mismo, aunque los mismos comuneros formaron grupos empresariales más pequeños atendiendo a la evolución de las comunidades tal como se ha señalado.

No solo se explica por el deseo de obtener algún apoyo del Estado, sino que los andinos ven que pueden relacionar su espíritu asociativo con la formación de empresas; es decir con la presencia de un gerente y una organización empresarial, las convergencias y las combinaciones forman parte de la historia andina.

b) Visión andina y presencia del Estado La visión andina ha sido frecuentemente enfrentada al Estado por los grupos contestarlos, veamos sus coincidencias y divergencias.

La visión andina del agua, con su flexibilidad y adaptabilidad, ha aceptado organizaciones especializadas de riego como los comités y comisiones de regantes, aunque su visión actual no es tan amplia, como para aceptar organizaciones que controlan grandes espacios como subcuencas y cuencas, apenas logran aceptar organizaciones más pequeñas como las de microcuencas y las organizaciones municipales distritales y no tanto de organizaciones, como las juntas de usuarios que controlan espacios mayores que está fuera de su cosmovisión.

Pese a ello, se ha constatado un esfuerzo de los andinos de adaptar estas organizaciones a su propia lógica, como las alianzas intercomunales para controlar el agua en espacios mayores, descritos por Fonseca y Mayer. Es cierto también, lo que se dijo en el taller, que aun siendo positivas la infraestructura y las organizaciones instaladas por el Estado, éste tiende a retirarse y no hacer un seguimiento a lo trabajado, de tal manera que no se consolida el sistema.

Si bien es cierto, se acepta las técnicas de riego difundidas por el Estado, no se coincide con la posición de entrada temporal del Estado, como la que hace FONCODES y PRONAMACHCS, las técnicas de riego requieren capacitación y diálogo constantes. Si bien, se acepta las normas básicas del Estado, éste último debe aceptar la organización comunal, como punto de partida para efectuar las tareas del riego y buen uso del agua potable. Si el andino es flexible para confluir, se requiere 
también de la flexibilidad del Estado para reconocer ciertos aspectos organizativos andinos, como las autoridades tradicionales del agua, como los cabildos de agua, los alcaldes de agua, los tomeros, quienes muy bien, pueden colaborar dentro de las organizaciones de regantes propuestas por el Estado.

Un debate que rebasa los límites de este trabajo son las posiciones vertidas por diferentes personas en el taller sobre la "Visión Andina del Agua” en el Cusco. Existió una posición que afirmaba que la cultura andina era original y ajena a la occidental y que por tanto la cultura occidental era opuesta y prescindible por los andinos. $\mathrm{Y}$ por ello, planteaba que los andinos no deben aceptar las organizaciones de regantes traídas por el Estado, que responden a la lógica occidental que busca tratar al agua, a los animales y a las plantas como recursos naturales comerciables, favoreciendo al individualismo, a diferencia de la lógica andina que trata a los recursos como seres vivos, favoreciendo a la comunidad y por tanto a la reciprocidad.

La otra posición señalaba que si bien los andinos estiman y valoran a su propia cultura, siempre han sido suficientemente abiertos y dúctiles para aceptar los aportes de las diversas culturas, entre ellas a la occidental, por tanto a la par que los andinos tratan a los seres vivos pueden tratar también a los recursos como naturales y comerciables. Esta actitud milenaria de la cultura andina la ha convertido en viva y cambiante, lo que ha hecho que haya aceptado muchas formas de organización como la de los regantes, conservando y transformando muchos de sus elementos originarios, no oponiendo la organización comunal a la de los regantes. Es posible que se incorpore la organización de los regantes propuesta por el Estado, aunque conservando lo esencial del espíritu comunitario.

Ambas posiciones son respetables y tienen que convalidarse con la investigación no solo sobre la base de algunos casos que puedan avalar cualquiera de ellas sino de la mayoría de nuestras actuales organizaciones comunales.

En todo este trabajo se ha tratado de demostrar que los andinos nunca han tenido una posición fundamentalista respecto a sí mismos, su propia lógica ha incorporado otros elementos y otras lógicas de las culturas que encuentran, amalgamando lo original con lo que inicialmente no lo es, pero que con el tiempo se convierte en una nueva originalidad. La cultura andina no es una visión fija que se repite a través de la historia sino que se va transformando en la interculturalidad.

c) Visión andina y mercado (Gráfico 5)

La visión andina de reciprocidad e intercambio con equidad es retada con la aparición de las exigencias del mercado. Se promociona a los andinos, instrumentos de gestión, para la mayor eficiencia en el uso del agua, empleando menos agua, aunque con vista a obtener mayores rendimientos. Se inicia una competencia mayor entre los usuarios y un conflicto mayor entre los comuneros y entre comunidades al competir por una mayor eficiencia para situarse mejor en el mercado. Si se aplicara la competencia para que todos ganen, usando la 
reciprocidad, estos conflictos se amenguarían o no se producirían. Se intensifica el uso del suelo para llenar las demandas del mercado, el agua de riego posibilita evitar la rotación de cultivos, sobre todo si un cultivo es probadamente rentable. Lo único que puede evitar este proceso de degradación de los suelos, condicionada por el mercado es la agricultura ecológica que rota y emplea cultivos asociados, ganando no tanto por volumen sino por el mayor precio que tiene en el mercado cada una de las unidades de los productos.

Las demandas del mercado obligan a una mayor producción y productividad. En la pequeña agricultura, las alianzas entre pequeños productores en cadenas productivas y entre comunidades, posibilitan una menor tendencia hacia el cubrimiento del mercado, en función de un afán lucrativo no tan desmedido como advierte el taller. Asimismo, la conservación de áreas de cultivos de consumo, posibilita la merma del espíritu mercantilista al tratar de vender todo al mercado para obtener más y más ganancias, sin importar la calidad del agua. Combinar cooperación efectiva con el mercado es posible aunque difícil, sin quebrar la organización comunal para la distribución del agua y el mantenimiento de la infraestructura hidráulica dentro de nuestras cuencas.

\section{d) Visión andina y Minería}

Un motivo especial dentro de la visión y el mercado es la necesidad de aplicar la interculturalidad en el diálogo necesario entre la minería y la agricultura. Hasta el momento, el mundo andino y el mundo empresarial, no se han comprendido, como hemos visto en el caso de Tambogrande y

Gráfico 5: LAS POSIII.IDADES DE CONVERGENCLA ENTRE

LA VISIÓN DE LA CULTURA ANDLNA Y DE LA OCCIDENTAL

\begin{tabular}{|c|c|c|}
\hline CULTURA ANONÁ & CULTURA DCCIDENTRL & CULTURA CHOLA \\
\hline 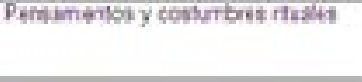 & 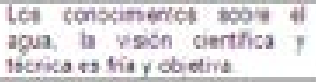 & 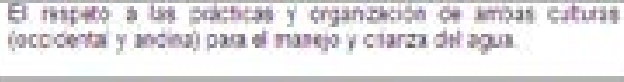 \\
\hline 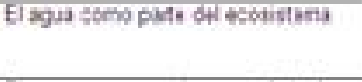 & 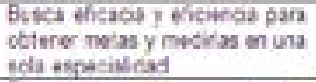 & 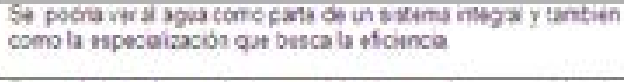 \\
\hline 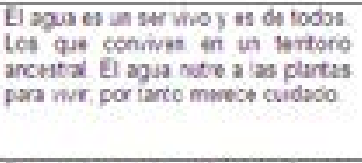 & 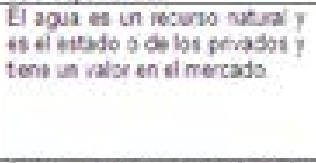 & 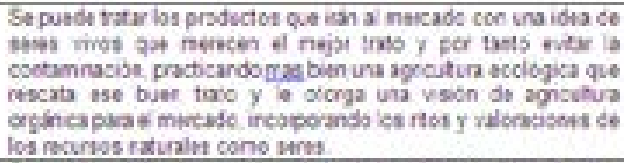 \\
\hline 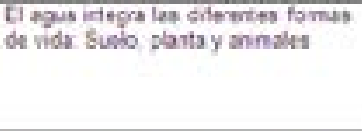 & 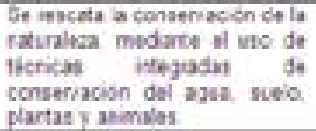 & 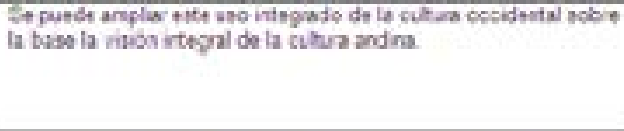 \\
\hline 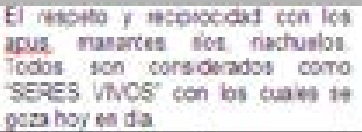 & 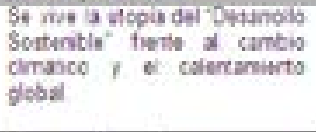 & 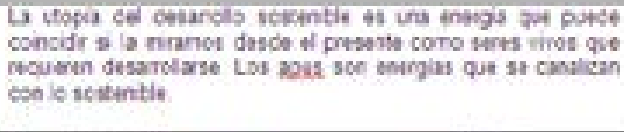 \\
\hline $\begin{array}{l}\text { Iac occiurbrus de papo a ia } \\
\text { Pachimama siempre se naloz. }\end{array}$ & 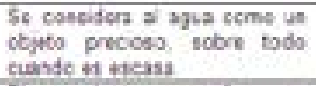 & 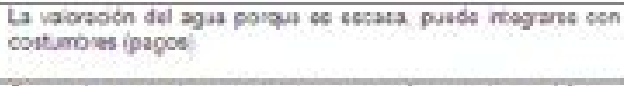 \\
\hline 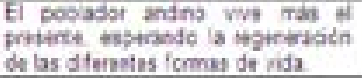 & 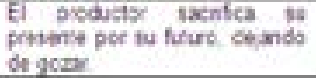 & 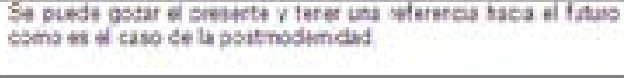 \\
\hline
\end{tabular}


Yanacocha. Las minas bajo sus propios supuestos culturales han querido solucionar el problema de la oposición o resistencia de las comunidades y caseríos andinos, no comprendiendo el significado simbólico de ciertos cerros donde habitan los apus, o los cerros protectores o los cerros fuentes de agua original, como es el caso del Cerro Quilish, que además tiene el significado simbólico de ser la unión entre el campo y la ciudad, entre lo rural y lo urbano en Cajamarca:

La mina ha querido solucionarlo todo con obras, dinero, empleo y captación de los líderes con limitados resultados. No ha comprendido el significado de la asamblea de los campesinos y lo que representan ciertos cerros y las acciones que había que hacer para explotar ciertas áreas con contenido simbólico. Además no ha comprendido la importancia de la agricultura, tanto para los habitantes que viven en el campo como en las ciudades.

e) La visión chola del agua ya existe En múltiples casos que sería largo describir, se ha constatado que los agricultores andinos, a su manera, han adoptado la organización oficial del agua, que proviene de la ley de aguas, normalmente escrita por profesionales, con alta cultura criollaoccidental.

Por ejemplo en el distrito de Santa María del Valle, en Huánuco, en un estudio que iniciamos en el CEPID de la Universidad Nacional Agraria La Molina, en el 2009, encontramos tres barrios (Taulligán, Casha y Huayrajirca), de una comunidad del mismo nombre, que se unieron para ampliar un canal rústico construido por una de ellas, que se llama Taulligán y construir un reservorio que les otorgue agua en tiempo de verano.

Ellos han formado un comité de regantes, que a su vez tiene tres subcomités quienes distribuyen el agua a través de agueros, quienes están a la orden de un supervisor que se llama delegado de aguas. Cada barrio tiene sus propios delegados de agua y agueros. Tanto el comité de regantes como los agueros y delegados de agua son elegidos en la asamblea comunal.

Y si existe descontento con el agüero en cuanto al reparto del agua $u$ otro problema, acuden al delegado de aguas y si este aún no resuelve, vuelve a la asamblea comunal, la cual, está encima del comité de regantes y de los comités por comunidad.

Lo único que funciona es el comité de regantes dentro de la estructura aceptada por la ley y la organización oficial. La comisión de regantes no está reconocida y no actúa, salvo, para ciertas autorizaciones que requieren, los comités acuden a una junta de usuarios, llamada Magra Mascarón, para resolver sus problemas con el Estado.

Es decir, han adoptado parte de la estructura propuesta por el Estado y han subsumido la organización formal del riego a la comunidad. Se ha comprobado que la organización funciona porque la estructura comunal, sirve para impulsar, supervisar y apoyar al comité de regantes y a los subcomités, hace faenas comunales para la limpieza del canal, con incluso 
no regantes, que en reciprocidad la comunidad les da agua para el consumo domésticos de sus casas y resuelve los conflictos en el reparto del agua y en el deterioro de la infraestructura de riego. Y no solo ello, sino que ha inventado este sistema de los delegados del agua y los agueros, todos bajo la autoridad comunal.

Sin embargo, esta estructura de organización funciona muy activamente solo en invierno, porque en verano el área se reduce de 300 hectáreas a 70 hectáreas sembradas; la mayor de los regantes, se van a trabajar como jornaleros en los cocales de la selva. En verano, ellos producen de todo como Alverja, chocho, habas, papa, maíz, lenteja, frejol canario, el trigo y cebada. En invierno, producen solo pepino, tomate y sobre todo frijol canario, en las partes más bajas de los cerros. Es decir que en invierno se produce solo 2 hectáreas promedio por regante y en verano se reduce a $1 / 4$ de hectárea, lo producido.

En un lugar tan diferente como lejano en la provincia de Celedín, en un canal de riego, llamado Sendamal El Toro, en un trabajo hecho con IPROGA y ITDG, se pudo constatar esta forma de organización mixta o mestiza, que le llamamos chola. En este caso, solo existía una comisión de regantes. Sin embargo, este canal tenía otros usuarios en la parte alta, quienes son ciudadanos del distrito de Huasmín, con más claras costumbres de carácter comunal.

Usan informalmente el agua del canal y han aceptado formar un comité que funciona solo para reparaciones del canal y no para pagar el uso del agua, porque ellos señalan que ellos la pueden pagar a través del trabajo. Finalmente, usan el agua para sembrar pastos cultivados, criar vacas, mejorar la calidad de su ganado y vender la leche a mejores precios a la empresa Gloria. Con este sistema, los 28 caseríos comprometidos por la organización formal del agua se han reducido a 18 , al no tener mayor beneficio del agua, cada vez más absorbida por los informales, que están bien organizados y con tremenda astucia como para abandonar sus incursiones, cuando existe mucha presión y volver a usar el agua cuando ésta se relaja.

Al final, los ganaderos de arriba le esta yendo mejor que a los de abajo. La organización del agua está siendo cambiada por los propios andinos, y adaptada por su propia voluntad colectiva, que mezcla el progreso con las costumbres andinas, muchas de las cuales, tienen sus antecedentes en la visión andina tradicional del agua, cuya transformación es evidente en una visión de la modernidad andina del agua. De esta manera, se está construyendo una modernidad a la manera andina, que es necesario, que en estudios posteriores, precisemos cómo es que se viene desarrollando, para que algún tiempo en el Perú, se incorpore el área andina como parte de los criterios para reajustar la ley de aguas, con una posición intercultural.

Esta choledad, esta vez acaecida en el campo, es menos transitoria que en la ciudad, donde los acondicionamientos para un mestizaje son mayores, los migrantes a la segunda o tercera generación pierden su condición de cholos y se convierten en mestizos, tal como lo vislumbraba José María Arguedas en su libro sobre "Forma- 
ción de una cultura nacional indoamerican":

“...El mestizo es el hombre más debatido del Perú y el menos estudiado. Naturalmente, no tomamos en consideración a quienes niegan su existencia. Nos bastará, para los fines de este artículo, señalar que hay infinidad de grados de mestizaje; que es muy distinto el que se forma en los pequeños pueblos de la sierra y el que aparece en las ciudades; que en lugares como Ayacucho o Huaraz, pueden encontrarse apenas diferenciados del indio y del que podríamos denominar representativo del hombre asimilado por entero a la cultura occidental..."

\section{CONCLUSIONES}

1. Estos retos de la geografía y montañas andinas han condicionado la formación de una visión andina del agua muy particular al combinar la creencia en que los elementos de la naturaleza son seres vivos y divinos que pueden agradecer o castigar según se les trate con ritos y ceremonias y se les cuide.

2. Se ha constatado que esta visión de los andinos que ha creado una cultura del agua no necesariamente se opone a todos los aspectos de la cultura occidental, más bien ocurre un sincretismo sin desaparecer la identidad de la visión andina del agua. Este sincretismo ha dado lugar a la formación de la cultura chola del agua.

3. Existen diversas visiones andinas del agua de acuerdo a cinco variables de diferentes influencias en la cultura andina, como es el caso de la ubicación de los hombres y mujeres andinos en los diferentes pisos ecológicos, las grandes distancias generacionales y de género que se han creado con el devenir de las ciudades y el mercado, las diferentes experiencias regionales y la diferentes participación e incorporación de los habitantes andinos en el mercado y las ciudades.

4. Se constatan profundas transformaciones de las visiones andinas del agua, producto de la mayor presencia de otras culturas que invocan a la interculturalidad en una relación más horizontal respecto al pasado.

5. Existen mejores condiciones como para que un futuro inmediato haya un reacomodo entre el Estado que tiende a reconocer mejor los valores andinos y los mismos andinos, cuya tendencia a ocultarse está perdiendo vigencia, a favor de una mayor transparencia y una mayor demanda para que sus derechos indígenas sean respetados, sin ser excluidos por los beneficios de pertenecer a un Estado nacional y ser ciudadanos tan iguales como los de las demás culturas de nuestra nación peruana y mundial.

\section{BIBLIOGRAFÍA}

ALLPANCHIS $2^{\circ} 28$. Antigüedad del riego en los andes. Volumen 2, Cusco 1986.

ALFARO Julio César; PAJARES Gonzalo; LLERENA, Carlos. Manejo de cuencas, riego y desarrollo rural en Gestión del Agua y crisis institucional, ITDG-SNVGPER, Lima 1992. 315 p. 
ALFARO, Julio César; CARDENAS, Alberto. Manejo de cuencas: Hacia una nueva estrategia del desarrollo rural en el Perú. Fundación.Friedrich Ebert, Lima 1990. $212 \mathrm{p}$,

ALFARO, Julio César. Estrategias para la gestión de las cuencas andinas, Revistas Tierra Nuestra, números 2, 3, 4/5, Departamento de Ciencias Humanas FEPUNALM, Lima 1996. 335 p.

ALFARO, Julio César; CHAVEZ, Julio; ESCOBAR, Emérita; MANDUJANO, María Beatriz; MARTINEZ, Galo; VALLEJOS Miriam; VILCAPOMA, José Carlos. Enfoque intercultural para la gestión de las microcuencas andinas, PRONAMACHCS-UNALM, Lima 2,002. $452 \mathrm{p}$.

ALFARO, Julio César (coordinador), APACLLA Ricardo; BERNEX Nicole; LLERENA Carlos; FELIPE MORALES, Carmen. Metodología para la Elaboración de planes maestros de cuencas, IPROGA Lima 1996. 78 p.

ALFARO, Julio César; GUARDIA Fernando; GOLTE, Jurgen; MASSON, Luis; ORÉ, María Teresa. Riego y organización social en Gestión del agua y crisis institucional. ITDG-SNV-GPER, Lima 1992. $315 \mathrm{p}$.

ALFARO, Julio César. Conflictos, gestión del Agua y cambio Climático, ITDG Unión Europea, Lima 2008. 123 p.

ALFARO, Julio César. El peligro del agua y la política peruana, CISEPA Pontificia
Universidad Católica del Perú PUCP, Revista Coyuntura, Lima 2009, 43 p..

AMAT Y LEÓN. El Perú nuestro de cada día. Universidad del Pacífico, Lima 2006. $205 \mathrm{p}$.

ARGUEDAS, José María. Formación de una cultura nacional indoamericana, siglo XXI 1998197 p.

BOELENS, Rutgerd; HOOGENDAM, Paul. Derecho de agua y acción colectiva, IEP Lima 2,001. 345 p.

BOELENS, Rutgerd. Buscando la equidad, Van Gorcum, Los Países Bajos 1998. $505 \mathrm{p}$.

CLAVERÍAS, Ricardo. Género e interculturalidad en los proyectos de riego. CIEDAGUALTIPLANO. Lima 2,002.

CONCHA, Pablo. Pueblos Indígenas Perú. CIED Lima 2,000. 146 p.

CLAVERÍAS, Ricardo. Desarrollo sostenible, consejo andino de manejo ecológico, Came La Paz Bolivia 1995. 228 p.

DOUROJEANNI, Axel. Políticas públicas para el desarrollo sustentable: La gestión integrada de cuencas. INRENA Lima 1994.

DE LA TORRE, Carlos. Importancia del análisis de actores para el estudio de los conflictos por el agua en el contexto cultural andino. Cochabamba Bolivia 2,003.

DE LA TORRE, Carlos; WASHINTON, Chañi. Promoviendo instituciones cam- 
pesinas para enfrentar el conflicto social e interculturalidad en el manejo del agua de riego en la sierra del Perú. Informe final proyecto del ITDG. Lima 2,002.

ESCALANTE, Carmen. El Agua en la cultura andina. Programa de Agua y Saneamiento, Banco Mundial, Lima 1999.

FONSECA, César; MAYER Enrique. Comunidad y producción en la agricultura andina. FOMCIENCIAS, Lima 1988. $212 \mathrm{p}$.

GRESLOU, Francois. Visión andina y usos campesinos del agua, en Sociedad y naturaleza en los andes. PRATEC Lima 1990.308 p.

GELLES. Paul. Agua y poder en la sierra peruana. PUCP Lima 2,002. 239 p.
MELGAR, Yenny (compilación). Perspectiva de género y rol de la mujer. CIEDAGUALTIPLANO Lima 2,002. 138 p.

ORÉ, María Teresa. Agua: Bien común y usos privados. PUCP-WAGENINGENITDG-WALIR, Lima Perú 2005. 246 p.

REVILLA, Luis. El Desarrollo y la interculturalidad en la experiencia del CESA en Desarrollo e interculturalidad en la zona andina. Documento de trabajo $\mathrm{N}^{\circ}$ 13 Escuela para el Desarrollo Lima 1998.

SOLIS, José. Gestión andina del riego. Ponencia en el Taller Visión Andina del Agua, GPER-INKA Cusco 2,003.

VASQUEZ, Absalón (autor); Alfaro, Julio César y otros (coautores). Manejo de cuencas altoandinas UNALM Lima 2,000. 516 p. 